Pay little, get little; pay more, get a little more: A framed forest experiment in Tanzania

Øyvind Nystad Handberg and Arild Angelsen 


\title{
Pay little, get little; pay more, get a little more: A framed forest experiment in Tanzania
}

\author{
Øyvind Nystad Handberg* and Arild Angelsen \\ School of Economics and Business, \\ Norwegian University of Life Sciences (NMBU), PO Box 5003, 1432 Ås, Norway \\ oyvind.handberg@nmbu.no \& arild.angelsen@nmbu.no
}

\begin{abstract}
How do different levels of individual payments for environmental services (PES) affect intrinsic and social motivations for forest conservation? Does introducing low levels of PES crowd out these motivations? This paper presents findings from framed field experiments (FFE) conducted with local forest users in Tanzania. The payoff structure represents a common-pool resource situation; participants' payoffs depend on the number of trees harvested, and aggregate over-harvesting can harm future harvest. Four levels of individual PES are tested in a between-group design: no ( $0 \%)$, low $(20 \%)$, medium $(60 \%)$ and full $(100 \%)$ PES, where the level is relative to the harvest value. We observe lower than theoretically predicted harvest rates at no, low and medium PES, while the opposite is true at full PES. Low PES has a weak negative effect on harvest rates among certain subgroups, while medium and full PES give strong reductions in harvest rates (c. $-43 \%$ and $-75 \%$ ). The results suggest that low PES has little impact on local forest use in Tanzania and has on aggregate a neutral effect on intrinsic and social motivations. Increasing payments has a negative, but diminishing effect on harvest rates.
\end{abstract}

JEL codes: C93; Q23

Keywords: Field experiment; PES; REDD; crowding-out; forest management; Tanzania

${ }^{*}$ Corresponding author at: School of Economics and Business NMBU, PO Box 5003, 1432 Ås, Norway. Tel: +476496 5690. 


\section{Introduction}

Result- or performance-based payments are increasingly proposed and implemented as a way to reach socially optimal outcomes, for example, in environmental conservation. Introducing pecuniary rewards begs the question at what level the reward should be set. A long-standing hypothesis - supported by some empirical studies - is that introducing cash payments can crowd out intrinsic or social motivations. ${ }^{1}$ Acts motivated by the inherent value of the act itself (intrinsic motivation) will become less attractive if an external intervention reduces the inherent value (Frey and Oberholzer-Gee 1997, Ryan and Deci 2000a, Bénabou and Tirole 2003). This negative impact might dominate the price effect of the incentive, and therefore reduce the supply of the action (Frey and Jegen 2001). Examples include blood donations (Titmuss 1970, Le Grand 2006), incentivised volunteering (Gneezy and Rustichini 2000), accepting the building of a nearby nuclear waste repository (Frey and Oberholzer-Gee 1997), and helping a fellow student load a sofa into a van (Heyman and Ariely 2004). The argument remain, nevertheless controversial and some have questioned its universal validity (e.g., Le Grand 2006).

This possible hidden cost of reward (Lepper and Greene 1978) has been explained in different ways. Incentivising certain actions could be interpreted as a lack of trust, which then leads to protest behaviour (Fehr and Falk 2002, Bénabou and Tirole 2006). Alternatively, the reward could dilute the pro-social signalling effect of the incentivized action (social image) (Bénabou and Tirole 2006, Ariely et al. 2009). Yet another explanation focuses on external rewards shifting the perceived responsibility of the task from the individual to some authority, allowing the individual to disclaim responsibility of the given task (Deci et al. 1999, Ryan and Deci 2000a).

One useful framework for analysing crowding out effects is the Self-Determination Theory (SDT) (Ryan and Deci 2000a, b). Ezzine-de-blas et al. (this issue) provide a summary and discussion of SDT, compare it with empirical findings, and present a conceptual framework of possible drivers. Four need satisfaction moderators - autonomy, competence, social relatedness and environmental relatedness - interact with the reward and lead to potential crowding-in and/or crowding-out effects. Generalizations are difficult to make; the specific features of an incentive scheme affect the moderators differently, and the moderators exist in a social context.

SDT is relevant for payment for environmental services (PES). PES is a voluntary transaction between service users and providers that are conditional on agreed rules of natural resource management for generating offsite services (Wunder 2015). The scheme often involves pecuniary incentives at the individual level (Pattanayak et al. 2010). The PES concept has strongly influenced the forest-climate discourse; the original idea of REDD+ (Reducing Emissions from Deforestation and forest Degradation) was to create a multi-level PES scheme, whereby pecuniary incentives, also at local levels, augment the carbon services provided by forests in developing countries (Angelsen and Rudel 2013). ${ }^{2}$

\footnotetext{
${ }^{1}$ In the following, 'other motivations' is used as an umbrella term for both intrinsic and social motivations.

2 Sustainable local forest use is both a coordination of forest users to ensure a good group outcome and an offsite service in providing carbon sequestration and storage. The REDD+ idea focuses on the latter, but can also help achieve the former.
} 
Local forest uses are not only motivated by material benefits and costs, but also by moral, ethical and cultural considerations (Ostrom et al. 1994, Levitt and List 2007, Henrich et al. 2010, FAO 2012). Other motivations play an important role in making decisions. The relationship between payments and pro-social behaviour might be non-linear; e.g., the S-shaped form suggested by Le Grand (2006). The recommendation by Gneezy and Rustichini (2000) is expressed in the title of their paper: "pay enough or don't pay at all". Therefore, REDD+ as an extrinsic reward can potentially crowd out other existing motivations in local forest users and produce adverse effects (Muradian et al. 2013). In this scenario, small payments could boost forest exploitation by crowding out these motivations, while not providing sufficiently large pecuniary incentives.

Research exploring the potential adverse behavioural effects of pecuniary incentives in local natural resource use is limited (Muradian et al. 2013, Wunder 2013). Even though experimental studies tend to find crowding-out effects of punishments (Cardenas et al. 2000, Vollan 2008), the results of payments is more ambiguous (e.g., Vollan 2008, Narloch et al. 2012, Muradian et al. 2013, Wunder 2013, Rode et al. 2014, Midler et al. 2015, Ezzine-de-blas et al. this issue).

This paper aims to investigate "how much is enough" through a series of framed field experiments (FFEs) with local forest users in Tanzania. Specifically, how is forest use affected by: (i) trivially low PES, (ii) medium PES where predicted impact depends, inter alia, on beliefs about the forest use of others, and (iii) full PES where there are no material incentives for local forest use?

The paper proceeds as follows. Section 2 describes the study area and the experiments conducted. Section 3 presents the results, and analyses how behaviour and treatment responses differ and how experimental behaviour corresponds with self-reported forest use (external validity). Section 4 discusses the results and raises critical methodological issues. Section 5 concludes.

\section{Experimental design and data collection}

\subsection{Study area}

About $80 \%$ of Tanzanian households rely on agriculture and natural resources for their livelihoods (TNRF 2009). The World Bank (2008: 16) estimates that "unaccounted-for services and non-industrial forestry reach 10 to 15 percent of GDP." Fuelwood constitutes the main source of energy for household cooking, heating and small-scale businesses such as curing tobacco and smoking fish (Johnsen 1999, World Bank 2008). Such use of forest resources tend to be especially important for low-income households (Angelsen et al. 2014).

Substantial parts of Tanzania's 35 million ha of forest is community owned or under de facto open access (Blomley and Iddi 2009, Zahabu et al. 2009, URT 2012, Treue et al. 2014). The forest cover is reduced at one of the highest rates in Africa (FAO 2011, URT 2012). The Tanzanian government seeks to address the problem, and became an early participant in the global REDD+ initiative. Tanzania entered a bilateral REDD+ agreements with Norway already in 2008, and is part of both the UN-REDD Programme and the World Bank's Forest Carbon partnership facility (FCPF). At the core of the REDD+ idea is performance-based payments for carbon 
storage in forests. It is seen as a relative quick and cheap way to mitigate climate change and has generated substantial attention and funds (Stern 2006, Angelsen and Rudel 2013).

The combination of high reliance on local subsistence use of forest resources, high deforestation and forest degradation rates, and several REDD+ pilot projects, makes Tanzania a highly relevant study area for understanding links between PES, other motivations and level of forest use.

\subsection{Data collection and sampling}

The experiments were conducted in the Tanzanian regions Geita, Kilimanjaro and Lindi in September-November 2014. Fifteen villages were selected in collaboration with local experts to ensure variation in location, local forest conservation initiatives, population size, major sources of livelihoods, distance to forest frontier, market access and distance to closest town. The villages, their attributes and locations are reported in Appendix II. Within each village, 32 participants were randomly selected by drawing from village household registers. ${ }^{3}$ The participants were then randomly allocated to four groups (of eight participants); each group constitutes an experiment session with a randomly predetermined treatment. The distribution of treatments on villages is also reported in Appendix II.

\subsection{Experimental design}

The experiment is a framed field experiment (FFE) (Harrison and List 2004), and builds on the design and payoff structure of Handberg and Angelsen (2015) ${ }^{4}$. Each group of participants is collectively endowed with a stock of 80 cardboard trees. Each tree (six cm tall, depicted in Figure 1) pays TZS 100 (c. USD 0.06) to the participant if harvested. In each round, the participants privately decide how many trees to harvest, with five trees being the technical upper limit. ${ }^{5}$ Decisions are made sequential, but as if simultaneous because trees harvested by a participant is replaced such that the next participant - within the same round - faces the same forest size. The aggregate harvest is revealed to the group at the end of each round. Afterwards the stock grows by two trees for every ten standing trees. This is repeated for nine rounds, or until the stock depletes to less than eight trees. The participants are perfectly informed about the parameters and the number of rounds. Taken together, the basic structure and payoff in the experiment create a collective action dilemma.

Estimating a sustainable harvest level through the nine rounds is challenging. Considering the nine rounds as a finite time set, one strategy is to not harvest in early rounds to boost the forest stock, which is completely harvested in later rounds. ${ }^{6}$ Alternatively, sustainable harvest could be the level that keeps the forest stock stable from round one. The sustainable harvest is then an aggregate harvest of 12 trees in each of the nine rounds. ${ }^{7}$

\footnotetext{
${ }^{3}$ If the selected household consisted of both a husband and a wife, a coin flip decided who was invited.

${ }^{4}$ Which again draws on Ostrom et al. (1994), Cardenas (2000), Cardenas (2004) and Rodriguez-Sickert et al. (2008).

${ }^{5}$ If the forest decreases to below 40 trees, the technical upper limit is given by the maximum harvest table presented in Appendix III. This is calculated to avoid a negative forest size, e.g., a forest size of 8-15 trees cannot supply more than one tree to each participant.

${ }^{6}$ No harvest in the first four rounds, 22 trees harvested in round five and 40 trees harvested in the last four rounds leaves 86 trees at the end of round nine, and an average aggregate harvest of 20.2 trees.

${ }^{7}$ An aggregate harvest of 12 trees the first round implies a new forest stock of 68 trees, which grows by 12 trees to 80 trees again before the next round.
} 


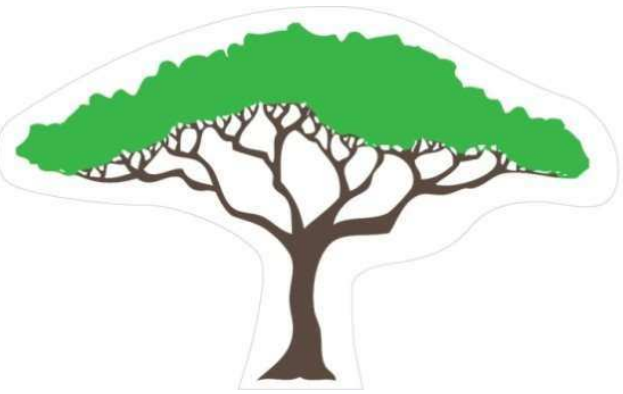

Figure 1: Tree used as token

One of four levels of PES is introduced randomly before the start of each session. The PES is a payment for not harvesting at the technical upper limit; e.g., harvesting three trees from a forest of 40 trees or more gives an extra payment of $5-3=2$. The magnitude of the PES is represented by the fraction of the value of a harvested tree (TZS 100), with treatments set at 0\%, 20\%, 60\% and $100 \%$ PES. $0 \%$ PES was introduced in 12 sessions, while the other three treatments were introduced in 16 sessions each (Appendix II). ${ }^{8}$

\subsection{Payoff structure, predictions and hypotheses}

Deriving the theoretically optimal strategies in the general case is complex, as the optimal strategies depends on respondents' particular motivations (material vs. other), beliefs about other players' strategies in current and future rounds, and possibly also beliefs about how own strategy affects future strategies of other players. We therefore discuss two simplified situations.

First, ignoring other motivations, the payoff $(y)$ of a forest user $i$ in a given round $t$ is given by the material payoff $(W)$ the user receives from each forest product harvested $\left(x_{i}\right)^{9}$ and potential $\operatorname{PES}(p) .{ }^{10} p$ is an individual payment for the difference between the upper limit of trees possible to harvest $\left(z_{t}\right)$ and the actual harvest $\left(x_{i t}\right)$. The level of $p$ directly affects the material payoffs. $p$ is given as a fraction of $W, p=\alpha W$, where $\alpha \in\{0,0.2,0.6,1\}$.

$$
y_{i t}=W x_{i t}+p\left(z_{t}-x_{i t}\right)=W x_{i t}+W \alpha\left(z_{t}-x_{i t}\right)
$$

Game theoretical predictions for individual material payoff-maximizing participants through the nine rounds are given in Appendix I. The optimal strategy under $0 \%$ and $20 \%$ PES is to maximize the number of trees harvested in each round, irrespective of the choices of the other participants in the same session. Under 60\% PES, the optimal strategy depends on the strategies of the others. If the aggregate harvest of others is very high or very low, the optimal strategy is to maximize harvest. If the aggregate harvest of others is at half of the limit, the optimal strategy is also to harvest half of the limit. Lastly, if the aggregate harvest of others is slightly below half of the limit, the optimal strategy is to harvest at slightly above the limit. With $100 \%$ PES, there is no incentive to harvest any trees.

\footnotetext{
${ }^{8}$ The design also involved an additional treatment, where half the sessions voluntarily chose to participate in the PES scheme and the other half had it imposed. This is the topic of another paper. The treatment was random and does not affect the conclusions of this paper.

${ }^{9}$ This is again a function of the previous harvests that has determined the current forest stock. This is excluded here for simplicity, but see Handberg and Angelsen (2015) for how it may be included.

10 An early version also included local public benefits from forests, such as soil erosion control, water purification, recreational opportunities, etc. In the experimental design, these benefits complicated the payoff structure. Pilot experiments revealed that most participants were unable to understand all parameters and make informed decisions.
} 
Next, we include moral and social payoffs (other motivations) related to use and non-use (conservation) of the forest $\left(M_{i}\right)$ (Cardenas 2000, Levitt and List 2007, Alix-Garcia et al. 2008, Rodriguez-Sickert et al. 2008). $M_{i}$ is a function of the harvested amount of forest products by user $i\left(x_{i}\right)$ and by the other users $\left(\sum x_{j \neq i}\right)$, and the size standing forest in the given time $\left(S_{t}\right)$. As such, this formulation includes the inherent value of the harvesting act itself, as well as the harvest's effect on others (e.g. lower forest stock). An important distinction is between other motivations for forest use and for forest conservation. The former includes motivations to harvest trees, while the latter includes motivations to not harvest. $M_{i}$ is a result of the socio-cultural environment of the population in the given situation. A major argument for conducting a framed field experiment with a relevant sample is to capture this context.

Our main interest is whether PES also affects moral and social payoffs. The full payoff function is then:

$$
y_{i t}=W x_{i t}+W \alpha\left(z_{t}-x_{i t}\right)+M_{i}\left(S_{t}, x_{i t}, \Sigma x_{j \neq i}, W \alpha\right)
$$

Considering the one-shot game, the first order condition is:

$$
\frac{\delta y_{i}}{\delta x_{i}}=W(1-\alpha)+\frac{\delta M_{i}}{\delta x_{i}}+\frac{\delta M_{i}}{\delta S} \frac{\delta S}{\delta x_{i}}=0
$$

Increasing harvest will increase material payoffs, except when $\alpha=1$. Other motivations for forest conservation are expressed through $\frac{\delta M_{i}}{\delta S} \frac{\delta S}{\delta x_{i}}<0$ (as own use has a negative stock effect, $\frac{\delta S}{\delta x_{i}}<0$ ). Other motivations for forest use are reflected in $\frac{\delta M_{i}}{\delta x_{i}}>0$, i.e., any personal preferences for using forest products beyond the material gains. Other motivations for forest conservation is thus decreasing in $x_{i}$, while other motivations for forest use is increasing in $x_{i}$. The net effect will vary across respondents and is likely to vary with the level of $x_{i}$. Moreover, and of special interest to us, the conservation motivation can be affected by the PES level $(\alpha)$, in particular as we move from zero to positive payment.

The repeated game is more complicated and predictions are less straightforward. Still, material payoffs from forest products and other motivations for forest use tend to positively affect harvest, while other motivations for forest conservation and (substantial) PES negatively affect harvest. $\alpha=0$ is the baseline the treatments are compared to. $\alpha=0.2$ is $20 \%$ PES, which does not affect a material payoff maximizer (Appendix I). Lowering the marginal material payoffs could make participants who are close to a negative first derivative to "tip over" and decrease their harvest. We assume that $\alpha=0.2$ is sufficiently low to make this effect irrelevant. $\alpha=0.6$ has a stronger negative impact on the material payoffs and affects material payoff maximizing forest users. $\alpha=1$ cancels out the material payoffs, leaving only moral and social payoffs to consider.

Our main hypotheses to test are then:

H1. Tanzanian forest users are not selfish material maximizers, i.e., $x_{\alpha=0}<1$

H2. Local forest users in Tanzania receive other payoffs than pure material ones from harvesting forest products, i.e., $x_{\alpha=1}>0$ 
H3a. Low level of PES crowds out other motivations for sustainable forest use among local forest users in Tanzania, i.e., $x_{\alpha=0}<x_{\alpha=0.2}$

H3b. Low level of PES crowds in other motivations for sustainable forest use among local forest users in Tanzania, i.e., $x_{\alpha=0}>x_{\alpha=0.2}$

Crowding-out of other motivations for conservation is thus taken to imply a higher mean harvest rate in the group with trivially low PES than in the group with no PES, and vice versa for crowding-in. We assume that random selection ensures comparability of the groups.

Examining treatment effects at the aggregate level could lead to a type II error if crowding-in and crowding-out effects neutralize each other. Based on the SDT framework of Ezzine-de-blas et al. (this issue), we therefore test four additional hypotheses:

H4. More positive attitudes towards the PES concept increases treatment effects (through moral responsibility) (crowding-in)

H5. Participating with family and/or close friends increases treatment effects (through social relatedness) (crowding-in)

H6. More real-life forest use decreases treatment effects (through environmental relatedness and/or insufficient compensation for opportunity costs) (crowding-out)

H7. Poverty decreases treatment effects (through social equity concerns) (crowding-out)

We furthermore test and discuss external validity, the role of gender and increasing PES levels.

\subsection{Methods for data analysis}

By having randomly sampled participants and randomly allocated treatments, we avoid many of the often-encountered challenges in analysing empirical data. Testing for differences in means across treatment groups is thus our main test.

Other analyses, including regression analyses, are done to test for robustness and how outcomes are affected by, for example, participant characteristics. The harvesting choices of a participant are not independent from each other, nor are they independent from the choices of other participants in the same session. The main test is therefore done at the session level $(N=60)$. To further understand the results and to look into individual level attributes, we also do OLS regressions at the individual $(N=480)$ and choice $(N=3824)$ levels. We attempt to control for the above-mentioned problems by including variables on lagged choices.

There is heterogeneity in village characteristics and in the experimental facilities, as well as a random and thus uneven distribution of treatments across villages (Appendix II). We thus apply village fixed effects in the regressions. We also apply robust standard errors in all regressions.

\section{Results}

\subsection{Non-parametric tests (H1-3)}

The dependent variable, harvest rate, is a participant's harvest as a fraction of the upper limit (expressed in the [0-1] interval or as percentage). This decision might be influenced by previous decisions of the participant and the other participants in the same session. For example, a 
participant might harvest more if the aggregate harvest in the previous round was high.

Therefore, the following tests will focus on the mean harvest rate through the nine rounds of the eight participants constituting a session, if not noted otherwise. Subsequent analyses of individual decision in each round will control for confounding factors.

Under $0 \%$ PES, the observed mean harvest rate is 0.57 (Table 1), substantially and significantly lower than the individually payoff maximizing strategy ("selfish strategy") of 1 . This supports H1. There is no significant difference between the mean harvest rates under $0 \%$ and $20 \%$ PES (thus not supporting $\mathrm{H} 3 \mathrm{a}$ nor $\mathrm{H} 3 \mathrm{~b}$ ), but the mean harvest rate declines significantly with higher levels of PES, and is only 0.14 for $100 \%$ PES. A significantly positive harvest rate under $100 \%$ PES supports $\mathrm{H} 2$.

In addition to the mean harvest rate, the spread of the individual decisions is noteworthy. Under $0 \%$ PES, only about $26 \%$ of the individual decisions $(d)$ follows the selfish strategy of maximum harvest, while $24 \%$ of the decisions are not harvesting any trees. These shares are decreasing and increasing, respectively, with higher payments, as expected. Under 100\% PES, $67 \%$ of the decisions is at the selfish strategy of no harvest, while $4 \%$ still harvest the maximum.

\begin{tabular}{lccc|cccccc} 
Table 1: Comparing hatvesting under neighbouring PES levels \\
\hline $\begin{array}{l}\text { PES } \\
\text { level }\end{array}$ & $\begin{array}{c}\text { Mean } \\
\text { harvest } \\
\text { rate }\end{array}$ & $\begin{array}{c}\text { Difference from } \\
\text { harvest rate of } \\
\text { the row above }\end{array}$ & $N$ & $d=0$ & $\begin{array}{c}d \epsilon \\
(0,0.4)\end{array}$ & $\begin{array}{c}d \epsilon[0.4, \\
0.6]\end{array}$ & $\begin{array}{c}d \epsilon \\
(0.6,1)\end{array}$ & $d=1$ & $N$ \\
\hline $0 \%$ & $\begin{array}{c}0.570 \\
(0.06)\end{array}$ & - & 12 & $24.2 \%$ & $12.2 \%$ & $27.5 \%$ & $10.5 \%$ & $25.6 \%$ & 632 \\
$20 \%$ & $\begin{array}{c}0.481 \\
0.041)\end{array}$ & $\begin{array}{c}0.089 \\
(0.07)\end{array}$ & 16 & $29.4 \%$ & $13 \%$ & $29.2 \%$ & $7.9 \%$ & $20.5 \%$ & 928 \\
$60 \%$ & $\begin{array}{c}0.326 \\
(0.031)\end{array}$ & $\begin{array}{c}0.155^{* * *} \\
(0.051)\end{array}$ & 16 & $36 \%$ & $20.8 \%$ & $29.7 \%$ & $4.2 \%$ & $9.4 \%$ & 1112 \\
$100 \%$ & $\begin{array}{c}0.142 \\
(0.022)\end{array}$ & $\begin{array}{c}0.184^{* * *} \\
(0.039)\end{array}$ & 16 & $66.6 \%$ & $15.3 \%$ & $12.8 \%$ & $1.5 \%$ & $3.9 \%$ & 1152 \\
\hline
\end{tabular}

Standard errors in parentheses. $* * *, * *, *$ : significant at the 1,5 or $10 \%$ level. $d$ is harvest decision.

Figure 2 compares the predicted harvest rates (see Appendix I) and the observed mean harvest rates. Under $0 \%$ and 20\% PES, the observed mean harvest rate is lower than the predicted harvest rate, i.e., the participants are not selfish payoff-maximizers, as is generally acknowledged in the literature (e.g., Andreoni 1990, Bolton and Ockenfels 2000, Fehr and Gächter 2000). The prediction under $60 \%$ PES depends on the beliefs on the strategies of others, but the observed mean harvest rate is significantly below even the lowest predicted harvest rate $(0.33$ vs. 0.5$)$. The higher harvesting than predicted under 100\% PES is also noteworthy, and we will return to this in the discussion. The estimated slope of the harvest line is c. -0.43, i.e., increasing PES by 1 percentage point (pp) lowers the harvest rate by 0.43 pp. ${ }^{11}$

\footnotetext{
${ }^{11}$ We assume linearity, and our results fit this assumption well.
} 


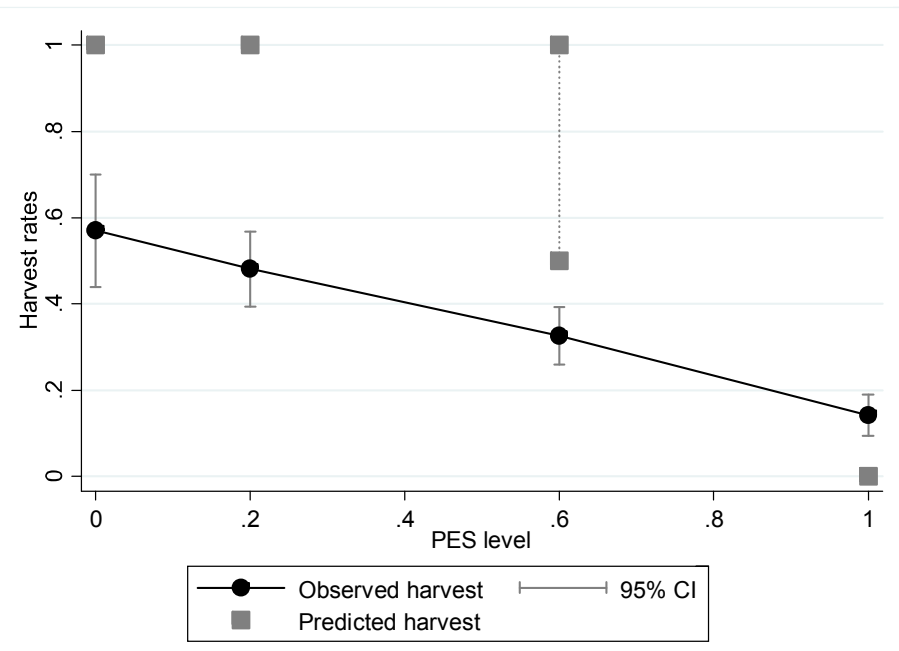

Figure 2: Predicted harvest rates and observed mean harvest rates ${ }^{12}$

Table 2 reports the fraction of forest stocks experiencing deforestation. For half of the groups with $0 \%$ and $20 \%$ PES, the forest stock depleted (to less than eight trees) before the ninth and last round. At higher levels of PES, the forest stock depleted for only one of the 32 groups, but under 60\% PES, half of the forests decreased to below the starting point. Under 100\% PES, the forest stock reduced for only one group.

Table 2: Fractions of forest stocks depleted or decreased during a session

\begin{tabular}{lcc}
\hline PES level & Stocks $<8$ trees before round nine & Stocks $<80$ trees after round nine \\
\hline $0 \%$ & $6 / 12$ & $11 / 12$ \\
$20 \%$ & $8 / 16$ & $13 / 16$ \\
$60 \%$ & $1 / 16$ & $8 / 16$ \\
$100 \%$ & $0 / 16$ & $1 / 16$ \\
\hline
\end{tabular}

\subsection{Regression analyses (H1-3)}

The regression models at the choice and individual levels presented in Table 3 control for the possibility that a harvest decision could be influenced by both the participant's earlier decisions and the aggregate decisions of others in earlier rounds. Model (1) regresses the individual harvest rates on the treatment variables (choice level, $N=3824$ ), models (2-3) do the same but includes control variables, while model (4) regresses participants' mean harvest rate through all the rounds of each participant on the treatment variables (individual level, $N=480)$. In model $(2), \frac{\sum x_{j \neq i, t-1}}{7}$ is the lagged average harvest rates of the other seven participants in the same session; model (3) also includes $x_{i t-1}$, the lagged harvest decision of the participant. Since the treatments are unevenly (although randomly) distributed across villages, village fixed effects are included in all models to control for possible biases.

Table 3: Regressing harvest rates at two levels on treatments and controls

\begin{tabular}{lcccc}
\hline & (1) Choice level & $\begin{array}{c}\text { (2) Choice level } \\
\text { w/control }\end{array}$ & $\begin{array}{c}\text { (3) Choice level } \\
\text { w/controls }\end{array}$ & $\begin{array}{c}\text { (4) Individual } \\
\text { level }\end{array}$ \\
\hline 20\% PES relative & -0.071 & -0.051 & -0.030 & -0.102 \\
to $0 \%$ PES & $(0.070)$ & $(0.049)$ & $(0.023)$ & $(0.077)$ \\
\hline
\end{tabular}

${ }^{12}$ Confidence intervals (CI) are at session level. 


\begin{tabular}{lcccc}
\hline $60 \%$ PES relative & $-0.209 * * *$ & $-0.143^{* * *}$ & $-0.064 * * *$ & $-0.262^{* * *}$ \\
to $0 \%$ PES & $(0.056)$ & $(0.041)$ & $(0.022)$ & $(0.060)$ \\
$100 \%$ PES relative & $-0.373^{* * *}$ & $-0.260^{* * *}$ & $-0.113^{* * *}$ & $-0.432^{* * *}$ \\
to $0 \%$ PES & $(0.061)$ & $(0.053)$ & $(0.023)$ & $(0.064)$ \\
$x_{i, t-1}$ & & $0.644^{* * *}$ & \\
& & & $(0.039)$ & \\
$\frac{\sum x_{j \neq i, t-1}}{7}$ & & $0.310^{* *}$ & 0.101 & \\
Constant & & $(0.130)$ & $(0.065)$ & \\
& $0.514^{* * *}$ & $0.355^{* * *}$ & $0.149 * * *$ & $0.579 * * *$ \\
$\mathrm{R}^{2}$ & $(0.047)$ & $(0.060)$ & $(0.029)$ & $(0.048)$ \\
$N$ & 0.136 & 0.144 & 0.464 & 0.250 \\
\hline
\end{tabular}

Robust standard errors in parentheses. ***, **, *: significant at the 1,5 or $10 \%$ level. Village fixed effects included, but not reported.

Table 3 supports the results of Table 1 and Figure 2; 60\% and 100\% PES have negative impacts on harvest rates, while 20\% PES has no significant impact. Model (2) suggests that the more other participants have harvested in previous rounds, the more a participant will harvest in the current round. However, model (3) does not find a significant effect of others lagged decision when own lagged decision is included. This indicates that participants are consistent in their decisions and do not rely on reciprocity (similar finding to Midler et al. 2015). The consistent strategy could nonetheless be affected by other motivations, but these motivations seem to be rather robust to others' choices.

\subsection{Further tests}

\subsubsection{More positive attitudes towards the PES concept increases treatment effects (H4)}

After the experiment session, participants were asked about their perceptions of the PES concept (given in Appendix III). On a scale from 1 to 5, where 5 is strongly agree and 1 is strongly disagree, they responded to the following statements: "it is right that those who benefit from the clean air that our forests produce, contribute to conserving the forest" (Q24), "it is not proven that paying for living trees decreases deforestation" (Q25), and "paying for living trees make other forest use considerations less important; like tradition, culture and religion" (Q26)." Figure 3 presents the effects of the four PES levels on individual mean harvest rates, by the participants' responses to the statements. The positives are those who "strongly agree" or "agree" on Q24 ( $=132)$ and those who "strongly disagree" or "disagree" on Q25 (N=338) and Q26 ( $N=88)$. The negatives are those who "strongly disagree" or "disagree" on Q24 $(N=280)$ and those who responded "strongly agree" or "agree" on Q25 (N=86) and Q26 ( $N=278)$. The ambivalent $(N=68+56+113)$ are excluded. ${ }^{13}$

There are no clear differences of the treatment effects across responses to the statements. In other words, attitudes towards PES do not seem to matter for the experimental behaviour and the impact of the intervention.

\footnotetext{
${ }^{13}$ One participant refused to respond to Q26.
} 
Interestingly, the majority of the participants thinks it is not right that those that benefit from their forest also contribute to conservation ( 280 vs. 132). The majority also thinks that it is not proven that paying for forest conservation works (338 vs. 86), and that the payments could make other considerations, such as traditions, culture and religion, less important (278 vs. 88 ).
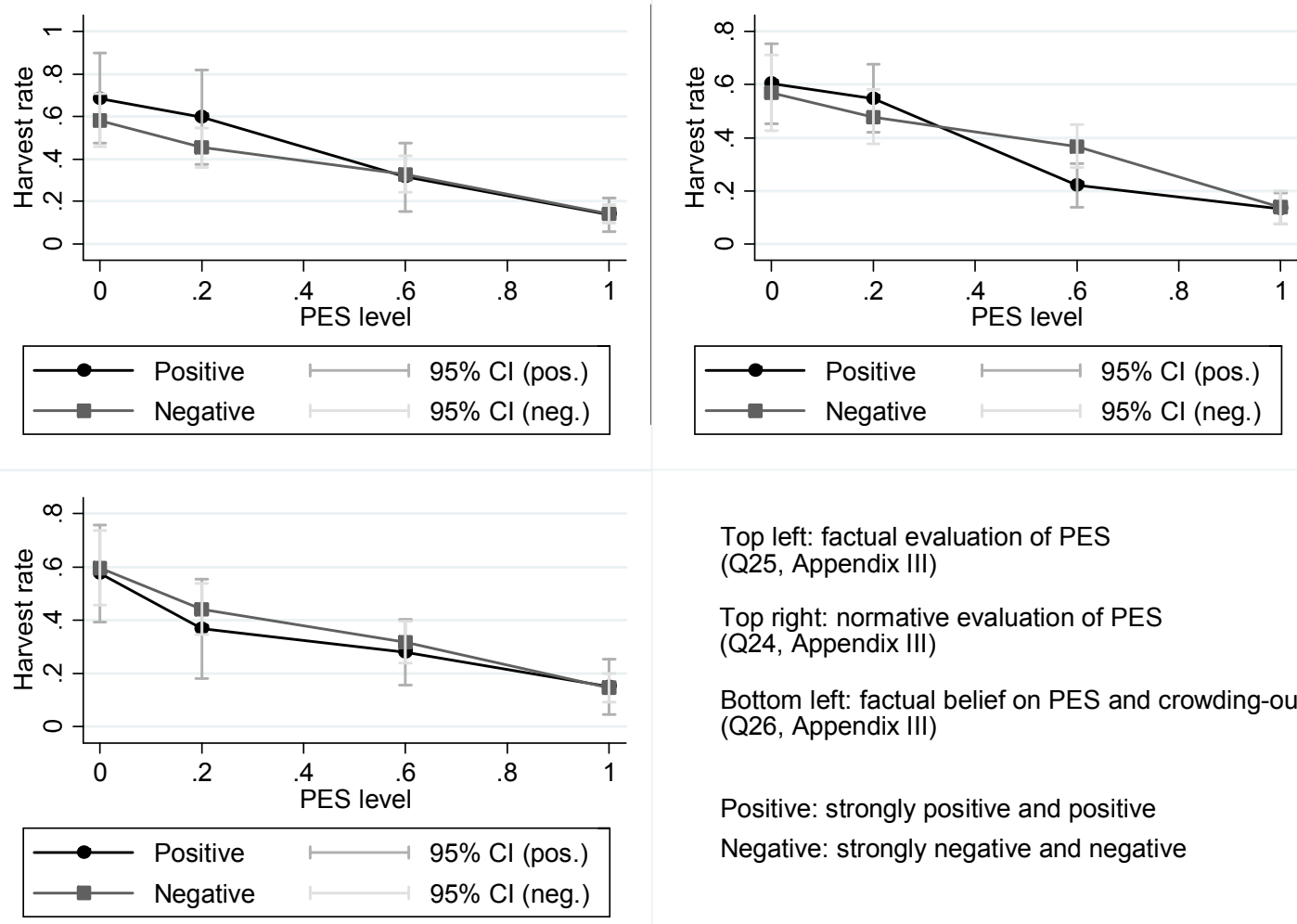

Top left: factual evaluation of PES (Q25, Appendix III)

Top right: normative evaluation of PES (Q24, Appendix III)

Bottom left: factual belief on PES and crowding-out (Q26, Appendix III)

Positive: strongly positive and positive Negative: strongly negative and negative

Figure 3: Treatment effects across different perceptions of PES

These responses could be taken to imply only weak demand for PES among the sampled Tanzanians. Alternatively, the statements and the scores used to evaluate them could be difficult for the participants to grasp. One indication in support for their validity is an intuitive correlation between the statements. The two factual evaluations are positively correlated, and these two statements are not correlated with the normative evaluation (Table 4).

Table 4: Correlation matrix of the three stated evaluations of the PES concept

Factual evaluation Normative evaluation Factual belief

(crowding-out)

\begin{tabular}{llll}
\hline Factual evaluation & 1 & & \\
Normative evaluation & $-0.049(0.284)[0.851]$ & 1 & \\
Factual belief & $0.284^{* * *}(0.000)[0.000]$ & $0.007(0.874)[1.000]$ & 1 \\
(crowding-out) & & \\
\hline $\begin{array}{l}\text { N=480. Standard significance levels in parentheses and Bonferroni corrected significance levels in brackets (Abdi } \\
\text { 2007). } * * *, * * *: \text { significant at the } 1,5 \text { or } 10 \% \text { level. }\end{array}$ \\
\hline
\end{tabular}

\subsubsection{Participating with family and/ or close friends increases treatment effects (H5)}

Social relatedness, measured as the number of (self-reported) family members or close friends participating in the same session, could affect harvest rates and the treatment effects. Hypothesis 5 states that the PES treatment is more effective in reducing harvest if social relatedness is high. 
Table 5 presents the results from regressing the mean individual harvest rate through the nine rounds on the interaction between the treatments and social relatedness (defined as a binary variable). Model (1) defines low social relatedness as no stated close friends or relatives in the same session $(N=318)$ and high social relatedness as 1-7 close friends or relatives in the same session ( $N=159)$. Model (2) robustness tests by slacking the former category also to include those who have one close friend or relative in the same session, which shifts 81 participants from the latter to the former category.

Table 5: Regressing harvest rates on treatments in interaction with social relatedness (soc-red)

\begin{tabular}{lcc}
\hline & $(1)$ & $(2)$ \\
\hline 20\% PES relative to 0\% PES & -0.129 & -0.115 \\
(low soc-red) & $(0.084)$ & $(0.085)$ \\
60\% PES relative to 0\% PES & $-0.299^{* * *}$ & $-0.269^{* * *}$ \\
(low soc-red) & $(0.062)$ & $(0.064)$ \\
100\% PES relative to 0\% PES & $-0.448^{* * *}$ & $-0.427 * * *$ \\
low soc-red) & $(0.071)$ & $(0.067)$ \\
High soc-red & -0.021 & -0.004 \\
& $(0.070)$ & $(0.094)$ \\
20\% PES relative to 0\% PES & 0.087 & 0.075 \\
*high soc-red & $(0.100)$ & $(0.103)$ \\
60\% PES relative to 0\% PES* & 0.102 & 0.043 \\
high soc-red & $(0.068)$ & $(0.093)$ \\
100\% PES relative to 0\% PES & 0.049 & -0.018 \\
$*$ high soc-red & $(0.080)$ & $(0.097)$ \\
Constant & $0.586 * * *$ & $0.579 * * *$ \\
& $(0.054)$ & $(0.053)$ \\
$\mathrm{R}^{2}$ & 0.255 & 0.250 \\
$N$ & 477 & 477 \\
\hline Robust standard errors in parentheses. *****,*: significant at the 1, 5 or 10\% level. \\
Village fixed effects included but not reported. & \\
\hline
\end{tabular}

The results of the two models are similar and the conclusions the same; social relatedness does not affect the harvest rates nor the treatment effects. We thus find no support for the hypothesis.

\subsubsection{More real-life forest use decreases treatment effects (H6)}

This hypothesis states that higher environmental relatedness and higher opportunity costs of conservation lead to crowding-out of other motivations for conservation.

The assumption for the test is that stated forest use (in the post-experiment interview) is positively correlated to environmental relatedness. Related, intensive forest users have a higher cost of reducing forest use than less intensive forest users; their opportunity cost of forest conservation is high. Thus, H6 predicts that the treatment effects is weaker among those with high stated forest use.

Table 6 uses four different binary variables as indicators of environmental relatedness or level of opportunity costs. Model (1) as being a commercial forest user $(N=61)$ or not $(N=419)$; model 
(2) as harvesting forest products more than once per week $(N=223)$, or once a week or less frequent $(N=257)$; model (3a) as using about the same or more forest products than other households in the village $(N=200)$, or less than others $(N=279)$; model $(3 \mathrm{~b})$ as using more forest products than other households in the village $(N=58)$, or less or about the same as others $(N=421)$. The latter category in each model indicates those with low environmental relatedness or low level of opportunity costs, whereas the latter category indicates the contrasting group.

Table 6: Regressing harvest rates on treatments in interaction with environmental relatedness (env-red)

\begin{tabular}{|c|c|c|c|c|}
\hline & $\begin{array}{l}\text { (1) Commercial } \\
\text { forest use }\end{array}$ & $\begin{array}{l}\text { (2) Absolute } \\
\text { forest use }\end{array}$ & $\begin{array}{l}\text { (3a) Relative } \\
\text { forest use }\end{array}$ & $\begin{array}{l}\text { (3b) Relative } \\
\text { forest use }\end{array}$ \\
\hline $20 \%$ PES relative to & -0.096 & -0.057 & -0.097 & -0.096 \\
\hline 0\% PES (low env-red) & $(0.08)$ & $(0.08)$ & $(0.08)$ & $(0.07)$ \\
\hline $60 \%$ PES relative to & $-0.243^{* * *}$ & $-0.190 * *$ & $-0.244 * * *$ & $-0.263 * * *$ \\
\hline 0\% PES (low env-red) & $(0.06)$ & $(0.07)$ & $(0.07)$ & $(0.06)$ \\
\hline $100 \%$ PES relative to & $-0.408^{* * *}$ & $-0.401 * * *$ & $-0.421 * * *$ & $-0.423 * * *$ \\
\hline 0\% PES (low env-red) & $(0.06)$ & $(0.07)$ & $(0.07)$ & $(0.06)$ \\
\hline $\begin{array}{l}\text { Commercial forest } \\
\text { user }(1=\text { yes })\end{array}$ & $\begin{array}{c}0.309 * * * \\
(0.06)\end{array}$ & & & \\
\hline Absolute forest use & & $\begin{array}{c}0.157 * * \\
(0.06)\end{array}$ & & \\
\hline Relative forest use & & & $\begin{array}{c}0.100^{* *} \\
(0.04)\end{array}$ & $\begin{array}{l}0.155^{*} \\
(0.08)\end{array}$ \\
\hline $20 \%$ PES relative to & $-0.168^{*}$ & -0.082 & -0.019 & -0.048 \\
\hline 0\% PES (high env-red) & $(0.09)$ & $(0.12)$ & $(0.09)$ & $(0.13)$ \\
\hline $60 \%$ PES relative to & $-0.194 *$ & $-0.154 * *$ & -0.047 & 0.004 \\
\hline $0 \%$ PES (high env-red) & $(0.10)$ & $(0.07)$ & $(0.08)$ & $(0.11)$ \\
\hline $100 \%$ PES relative to & $-0.271 * *$ & -0.051 & -0.031 & -0.104 \\
\hline 0\% PES (high env-red) & $(0.12)$ & $(0.09)$ & $(0.05)$ & $(0.11)$ \\
\hline Constant & $\begin{array}{c}0.548^{* * *} \\
(0.05)\end{array}$ & $\begin{array}{c}0.500^{* * *} \\
(0.05)\end{array}$ & $\begin{array}{c}0.539 * * * \\
(0.05)\end{array}$ & $\begin{array}{c}0.561 * * * \\
(0.05)\end{array}$ \\
\hline $\mathrm{R}^{2}$ & 0.280 & 0.273 & 0.264 & 0.267 \\
\hline$N$ & 480 & 480 & 479 & 479 \\
\hline
\end{tabular}

Robust standard errors in parentheses. ${ }^{* * *},{ }^{* *}, *$ : significant at the 1, 5 or $10 \%$ level. Village fixed effects included but not reported.

First, Table 6 supports earlier findings that $60 \%$ and 100\% PES have negative impacts on harvest rates, and that stated forest uses and harvesting in the experiment are positively correlated (which will be discussed later). Second, in examining the interaction effect between the treatments and the stated forest use variables, there is no support for H6 in any of the four models; the treatment effects are not weaker among participants with high environmental relatedness (high-rel) (or the ones with high opportunity costs). If anything, the treatment effect is stronger among commercial forest users (significant at the 10\% level with $20 \%$ and $60 \%$ PES, and at the 5\% level with 100\% PES) and among high absolute forest users (significant at the 5\% level with 60\% PES). 
One could argue that environmental relatedness should be measured differently, e.g., commercial forest users have lower environmental relatedness than non-commercial users (opposite of model (1)). In this interpretation, the finding in model (1) support H6; the treatment effects is significantly weaker with high environmental relatedness. The other indicators of environmental relatedness, models (2-3b), do however not support this tendency. In sum, we are reluctant to support H6.

\subsubsection{Poverty decreases treatment effects (H7)}

According to this hypothesis, poor participants should be less responsive to the treatment. The individual PES applied here compensates the (relatively) rich as much as the poor, even though the latter group is more vulnerable. The treatment thus scores low on the social equity concerns of Ezzine-de-blas et al. (this issue), which may lead to a crowding-out effect among the poorer participants. The wealth indicator used is the type of roof the participant possesses. If reported roof is predominately made of thatch, he or she is relatively poor, and if the stated roof is predominately made of tin, he or she is relatively rich (although most are still poor in a global perspective). Figure 4 presents the mean harvest rates under the four PES levels, by the poor $(N=125)$ and the rich $(N=351)$.

The figure indicates that the harvest rates of the poor and rich are similar under $60 \%$ and $100 \%$ PES. Under $0 \%$ and $20 \%$ the harvest rates in the two wealth categories cross. Table 7 further examines the treatment effects in interaction with the wealth indicator. The table reports the effect on (individual level) mean harvest rate by the treatments in interaction with roof type. Variables on stated forest use and literacy are included in model (2), as they can be confounding factors (the poor tend to be more reliant on forest use and are more likely to be illiterate).

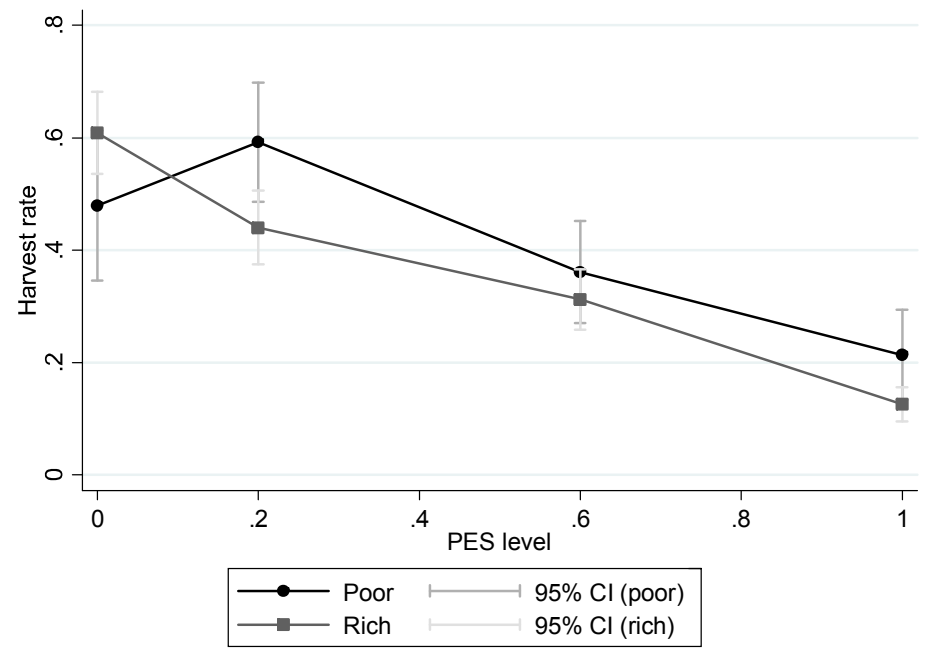

Figure 4: Mean harvest rates under the four PES levels by a wealth indicator (standard errors at participant level)

Table 7 supports the findings of Figure 4; wealth has no clear impact on harvest rates (significant at the 10\% level in model (2) and insignificant in model (1)). 20\% PES significantly lowers mean harvest rates among rich participants, but not among the poor participants. We thus find some support for hypothesis 7; the treatment effect is weaker among poor participants. 


\begin{tabular}{|c|c|c|}
\hline & (1) Without controls & (2) With controls \\
\hline $20 \%$ PES relative to $0 \%$ PES & 0.116 & 0.088 \\
\hline (poor) & $(0.110)$ & $(0.098)$ \\
\hline $60 \%$ PES relative to $0 \%$ PES & -0.110 & -0.118 \\
\hline (poor) & $(0.077)$ & $(0.073)$ \\
\hline $100 \%$ PES relative to $0 \%$ & $-0.296 * * *$ & $-0.305^{* * *}$ \\
\hline PES (poor) & $(0.099)$ & $(0.082)$ \\
\hline \multirow[t]{2}{*}{ Roof type $(1=$ tin $)$} & 0.139 & $0.145^{*}$ \\
\hline & $(0.095)$ & $(0.081)$ \\
\hline $20 \%$ PES relative to $0 \%$ PES & $-0.294 * *$ & $-0.268^{* *}$ \\
\hline *rich & $(0.113)$ & $(0.110)$ \\
\hline $60 \%$ PES relative to $0 \%$ & $-0.210^{* *}$ & $-0.196^{*}$ \\
\hline PES*rich & $(0.089)$ & $(0.092)$ \\
\hline $100 \%$ PES relative to $0 \%$ & $-0.181 *$ & $-0.171^{\prime}$ \\
\hline PES * rich & $(0.089)$ & $(0.075)$ \\
\hline \multirow[t]{2}{*}{ Relative forest use } & & $0.031^{*}$ \\
\hline & & $(0.010)$ \\
\hline \multirow[t]{2}{*}{ Absolute forest use } & & $0.027 * *$ \\
\hline & & $(0.010)$ \\
\hline \multirow{2}{*}{$\begin{array}{l}\text { Commercial forest user } \\
(1=\text { yes })\end{array}$} & & $0.098^{* *}$ \\
\hline & & $(0.038)$ \\
\hline \multirow[t]{2}{*}{ Literacy } & & $-0.069 * *$ \\
\hline & & $(0.026)$ \\
\hline \multirow[t]{2}{*}{ Constant } & $0.477 * * *$ & $0.424 * * *$ \\
\hline & $(0.088)$ & $(0.081)$ \\
\hline $\mathrm{R}^{2}$ & 0.280 & 0.336 \\
\hline$N$ & 476 & 473 \\
\hline
\end{tabular}

\subsubsection{Gender differences}

Previous experimental studies find clear gender-specific behaviour and treatment effects (Croson and Gneezy 2009, Cardenas et al. 2014, Handberg and Angelsen 2015). Related to forest use in Tanzania, gender roles are important, as women tend to be responsible for household collection and use of forest products (Johnsen 1999, FAO 2001, World Bank 2010). In the related study of Handberg and Angelsen (2015), women harvest significantly more than men, and the treatment effects are stronger among women than men.

This study finds no gender difference in harvest rates without treatment, as reported in Table 8. Further, the treatment effects are stronger among men than among women. Among men (at the individual level), 20\% PES lowers the harvest rate by 19 pp (significant at the 5\% level); 60\% and $100 \%$ PES lowers the harvest rate by $29 \mathrm{pp}$ and $45 \mathrm{pp}$ respectively (significant at the $1 \%$ level). Among women (at the individual level), the effect of 20\% PES is not present, $60 \%$ PES lowers the harvest rate by $23 \mathrm{pp}$ (significant at the 5\% level) and 100\% PES lowers the harvest rate by $42 \mathrm{pp}$ (significant at the $1 \%$ level). 


\begin{tabular}{|c|c|c|}
\hline & (1) Choice level & (2) Individual level \\
\hline $20 \%$ PES relative to $0 \%$ PES & $-0.062^{* *}$ & $-0.191^{* *}$ \\
\hline$($ men $)$ & $(0.028)$ & $(0.081)$ \\
\hline $60 \%$ PES relative to $0 \%$ PES & $-0.083^{* * *}$ & $-0.287 * * *$ \\
\hline (men) & $(0.025)$ & $(0.059)$ \\
\hline $100 \%$ PES relative to $0 \%$ PES & $-0.123 * * *$ & $-0.452 * * *$ \\
\hline (men) & $(0.025)$ & $(0.051)$ \\
\hline \multirow[t]{2}{*}{ Gender (1=woman) } & -0.012 & -0.030 \\
\hline & $(0.019)$ & $(0.043)$ \\
\hline $20 \%$ PES relative to $0 \%$ PES & 0.050 & 0.160 \\
\hline$*_{\text {women }}$ & $(0.047)$ & $(0.094)$ \\
\hline $60 \%$ PES relative to $0 \%$ & 0.027 & 0.056 \\
\hline PES*women & $(0.039)$ & $(0.089)$ \\
\hline $100 \%$ PES relative to $0 \%$ PES & -0.006 & 0.028 \\
\hline *women & $(0.025)$ & $(0.059)$ \\
\hline \multirow[t]{2}{*}{$x_{i, t-1}$} & $0.618^{* * *}$ & \\
\hline & $(0.042)$ & \\
\hline$\underline{\sum x_{j \neq i, t-1}}$ & 0.108 & \\
\hline 7 & $(0.069)$ & \\
\hline \multirow[t]{2}{*}{ Age } & -0.002 & -0.003 \\
\hline & $(0.001)$ & $(0.003)$ \\
\hline$A g e^{2}$ & $0.003 * *$ & $0.006^{* *}$ \\
\hline$\overline{100}$ & $(0.001)$ & $(0.003)$ \\
\hline Relative forest use (middle & 0.015 & 0.036 \\
\hline third relative to bottom third) & $(0.011)$ & $(0.025)$ \\
\hline Relative forest use (upper & $0.045^{* *}$ & $0.094 * *$ \\
\hline third relative to bottom third) & $(0.019)$ & $(0.038)$ \\
\hline \multirow[t]{2}{*}{ Absolute forest use } & $0.008^{*}$ & $0.026^{* *}$ \\
\hline & $(0.004)$ & $(0.010)$ \\
\hline \multirow{2}{*}{$\begin{array}{l}\text { Commercial forest user } \\
(1=\text { yes })\end{array}$} & $0.045^{* *}$ & $0.106^{* *}$ \\
\hline & $(0.018)$ & $(0.039)$ \\
\hline \multirow[t]{2}{*}{ Constant } & $0.166^{* * *}$ & $0.530 * * *$ \\
\hline & $(0.041)$ & $(0.087)$ \\
\hline $\mathrm{R}^{2}$ & 0.474 & 0.338 \\
\hline$N$ & 3340 & 479 \\
\hline
\end{tabular}

Figure 5 depicts the harvest rates for women and men separately for the four levels of PES. As indicated above, the main difference between the genders is the effect of $20 \%$ PES. An F-test of equal harvest rates between the genders reveals that the hypothesis of equality at $20 \%$ PES can be rejected ( $p$-value 0.03). Equality of harvest rates between the genders at $0 \%, 60 \%$ and $100 \%$ PES cannot be rejected ( $p$-values at $0.85,0.86$ and 0.4 respectively). 20\% PES thus has an impact on male (significant at the $5 \%$ level), but not female, harvest rates, while the other PES levels have similar impacts on men and women. 


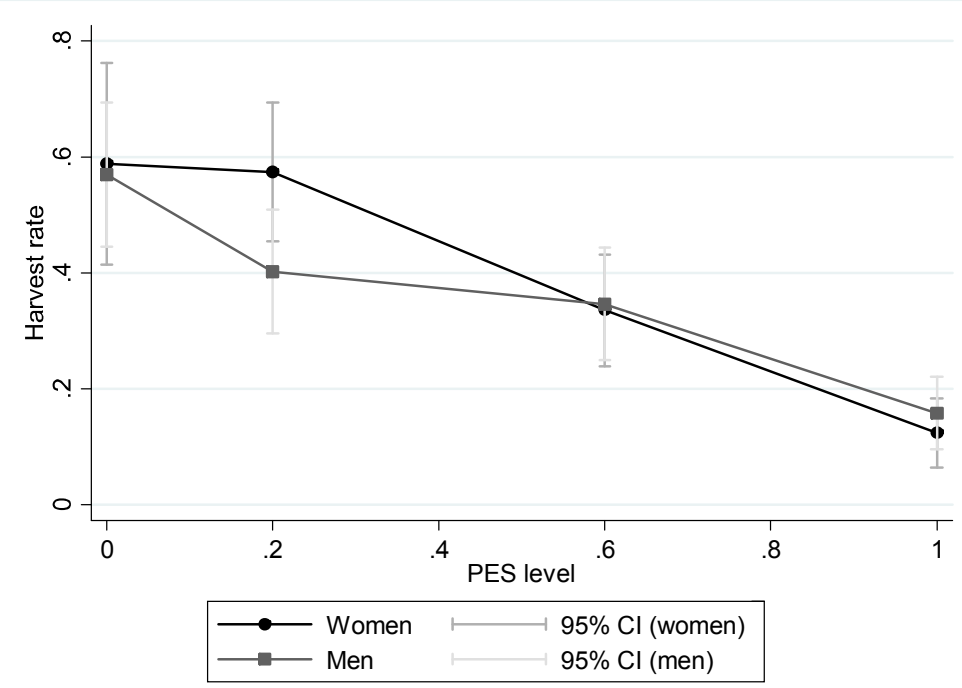

Figure 5: Harvest rates under the four PES levels by gender

Also revealed by Table 8, age has no clear impact on harvest rates, unlike in Handberg and Angelsen (2015). ${ }^{14}$ The lagged variables in model (1) report similar coefficients as in Table 3.

\subsection{External validity}

The main test conducted for external validity is the degree to which behaviour in the experiment correlates positively to self-reported forest use. In the post-experiment interview, participants were asked about their relative forest use (if the household collects less, about the same or more forest products than other households in the village), absolute forest use (number of times per week the household collects forest products) and commercial forest use (if the household sells forest products or not).

Table 8 reports the partial correlation between the stated forest use variables on harvest rates in the experiment. The harvest rate of a participant stating to be in the top third of forest products use in the village, is 5-9 pp higher than the bottom third; another weekly trip in the forest corresponds to a 1-3 pp increase in harvest rate; and commercial forest users harvest 5-11 pp more than others. Similar relationships are reported in Table 6 and Table 7. Taken together, there is a positive correlation between stated forest use and forest use in the experiment, supporting the behavioural validity ${ }^{15}$ of the study.

Table 9 presents the mean stated forest uses and their simple correlations to the observed mean harvest rate at the participant level by the PES levels. ${ }^{16}$ We fail to reject equality between the mean stated forest uses across treatment groups at the 5\% significance level, except for means in absolute forest use in 20\% and 60\% PES and in commercial forest use between 20\% and 100\% (F-test with $p$-value 0.024 and .012 , respectively). The means are thus mostly comparable. The table further reveals that under $0 \%$ and $100 \%$ PES, there is strong and significant correlations between mean harvest rate and both absolute and relative forest use. These correlations are not

\footnotetext{
${ }^{14}$ Handberg and Angelsen (2015) find a quadratic relationship between age and harvest rates, which is neither refuted nor supported here. This suggests that the results are context specific, even within the same country. 15 Behavioural validity refers to the external validity of the general behaviour of the participants. Treatment validity refers to the external validity of the treatments (Handberg and Angelsen 2015).

${ }^{16}$ There are thus 128 observations in each cell, except for relative forest use under 20\% PES, with 127 observations and all cells under $0 \%$ PES, with 96 observations each.
} 
as strong under the two intermediate PES levels. Regarding commercial forest use, there is correlation at (the 1\% level) under $0 \%$ PES and (at the 10\% level) under $20 \%$ and $60 \%$ PES. The differences in the other three levels will be discussed in the next section.

Table 9: Stated forest uses and the correlation to experiment mean harvest rates by treatment groups

\begin{tabular}{lcccccc}
\hline PES level & \multicolumn{2}{c}{ Absolute forest use } & \multicolumn{2}{c}{ Relative forest use } & \multicolumn{2}{c}{ Commercial forest use } \\
\hline & Mean value & Correlation & Mean value & Correlation & Mean value & Correlation \\
\hline $0 \%$ & 1.671 & $0.258^{* *}$ & 1.521 & $0.216^{* *}$ & 0.104 & $0.338^{* * *}$ \\
& $(0.179)$ & $(0.011)$ & $(0.071)$ & $(0.035)$ & $(0.031)$ & $(0.001)$ \\
$20 \%$ & 1.815 & $0.203^{* *}$ & 1.551 & 0.142 & 0.195 & $0.157^{*}$ \\
& $(0.142)$ & $(0.022)$ & $(0.061)$ & $(0.110)$ & $(0.035)$ & $(0.076)$ \\
$60 \%$ & 1.365 & 0.132 & 1.555 & $0.175^{* *}$ & 0.117 & $0.168^{*}$ \\
& $(0.137)$ & $(0.138)$ & $(0.064)$ & $(0.049)$ & $(0.029)$ & $(0.059)$ \\
$100 \%$ & 1.475 & $0.248^{* * *}$ & 1.523 & $0.178^{* *}$ & 0.086 & 0.097 \\
& $(0.141)$ & $(0.005)$ & $(0.063)$ & $(0.045)$ & $(0.025)$ & $(0.277)$ \\
\hline
\end{tabular}

Bonferonni corrected significance levels in parentheses. ${ }^{* * *}, * *, *$ : significant at the 1,5 or $10 \%$ level.

\section{Discussion}

\subsection{Harvesting behaviour}

The harvest rate under no PES is significantly below the payoff-maximizing strategy. This is consistent with existing experimental literature on common pool resources (e.g., Cardenas 2000, Handberg and Angelsen 2015, Midler et al. 2015). The harvest rate is, however, high enough to lower the forest size in most sessions and to deplete it completely in half of the sessions under no and low PES (14/28). This calls for measures to limit harvesting.

The mean harvest rate is higher than the mean harvest rate of Handberg and Angelsen (2015). The main differences between the experiment designs are the number of rounds (nine vs. six), information about the number of rounds (known vs. unknown), and the sampling areas within Tanzania. A likely candidate for driving the difference is the information provided. By knowing the number of rounds, sophisticated participants could use backward induction to decide upon their decisions, thus pulling the mean upwards. Participants in the study of Handberg and Angelsen (2015) were unable to do so.

There is large heterogeneity in harvest decisions, particularly for low PES levels. Only about 28\% of the decisions under no PES is in the range 0.4-0.6, while $26 \%$ of the decisions is at the upper limit and $24 \%$ of the decisions are at zero (Table 1). It is thus more the extreme decisions that pull the mean towards 0.57 than participants choosing to harvest about half of the upper limit. The compromise effect, a bias towards choosing the middle option of a choice set (Simonson 1989), is therefore not driving the result.

The mean is a useful indication of overall forest use and effects of conservation efforts. Yet, only focusing on mean harvest rates would hamper our understanding of forest use. Heterogeneity among local forest users is important in planning and evaluating conservation efforts. Focusing on high deforesters/forest users could in some contexts be more effective than a broad approach to reach everyone. 


\subsection{Treatments}

\subsubsection{Material payoffs and other motivations (H1-2)}

Mean harvest rates are significantly lower than 100\% under 0\% PES and significantly higher than 0\% under 100\% PES, thus supporting hypotheses one and two. Decisions are also made by intrinsic and social motivations and not only own material payoffs. Two confounding effects could, however, influence the results.

The lower than predicted harvest rates are likely in part due to scrutiny effects (or experimenter demand effects) creating a pro-social bias (Lusk et al. 2006). In the experiment, participants' choices are not linked to their name and are not revealed to the other participants. Still, the enumerator observing and taking note of the choices is likely to reduce harvesting. Field experiments comparing scrutinized choices and anonymous choices tend, however, to find smaller scrutiny effects than the difference observed here (Lusk et al. 2006, Benz and Meier 2008, Martin and Randal 2011, Ekström 2012).

Another possible driver for the low harvest rate under 0\% PES and the high harvest rate under $100 \%$ PES is participants not fully understanding the experiment. ${ }^{17}$ Non-informed decisions are to be expected, also in real life decision making. These errors can only drive the results in one direction compared to the prediction (downwards under 0\% PES and upwards under 100\% PES), and could therefore in part explain the findings. That the treatments that affect the predicted strategies have significant impacts on harvest decisions is an indication that a substantial part of the participants understood the experiment; as is the positive correlation between stated forest use and experiment decisions. Moreover, if choices are random they should centre around the mean, but Table 1 reveals that large parts of the decisions are at the extremes.

As also observed in real life Tanzanian local forest use (Lund and Treue 2008, Blomley and Iddi 2009, Treue et al. 2014), other motivations should constitute part of the [1-0.57] interval. This difference is what is prone to crowding-out effects. A rather strong and significantly positive mean harvest rate under 100\% PES indicates that there are other motivations, not only for forest conservation, but also for forest use. Distinguishing between other motivations for use and for conservation could therefore be useful when considering crowding-out effects. Mental accounting (Thaler 1985) is also relevant for the observed harvest under 100\% PES. By allocating resources in categories, we become less price sensitive. These aspects are further be discussed in 4.2.3.

\subsubsection{Crowding-out and participant characteristics (H3-7)}

$20 \%$ PES has no significant impact on the aggregate mean harvest rate. As this PES level is sufficiently low not to alter the optimal strategy of payoff-maximizers, the lack of impact suggests that the payment, in sum, crowds neither out nor in other motivations. There is thus no support for neither $\mathrm{H} 3 \mathrm{a}$ nor $\mathrm{H} 3 \mathrm{~b}$.

\footnotetext{
${ }_{17}$ Great care was taken during instructions to ensure that the participants understood the mechanisms, parameters and consequences of their choices. Also, the enumerator observing harvest decisions informed each participant about the earnings their choice generated.
} 
Analysing the treatment effects by sub-groups could reveal if there is any crowding-out or crowding-in effects occurring through some of the moderators suggested by Ezzine-de-blas et al. (this issue): moral responsibility (H4), social relatedness (H5), environmental relatedness/heterogeneity in opportunity costs (H6) and social equity concerns (H7). Attitudes towards PES, participating with family or close friends and stated forest use do not affect treatment effects, leaving little support for H4-H6.

Testing treatment effects in interaction with the poverty indicator reveals that $20 \%$ and $60 \%$ PES decrease forest use among the relatively rich, but not among the poor. The finding relates to $\mathrm{H} 7$, but does not necessarily support the hypothesis. $\mathrm{H} 7$ states that due to social equity concerns, the poor could perceive an equal compensation for both groups as unfair and hence reduce their other motivations for forest conservation. The flipside of $\mathrm{H} 7$ is that the scheme increases other motivations among the rich to reduce forest use (they are more capable and should therefore take more responsibility to conserve the forest, i.e., they subsidize the poor). Thus, there is a crowding-in effect of $20 \%$ PES among the richer participants. Trivially low incentives could thus reap the lowest hanging fruits by decreasing forest use among the better-off participants, but not enough to create a significant effect at the aggregate level.

A crowding-in effect is also observed among men. ${ }^{18}$ 20\% PES significantly decreases the mean harvest rate among men, but not among women. The lack of significant difference in female and male harvest rates under no PES and the difference under 20\% PES could be due to genderroles being sample-specific (Sunderland et al. 2014). ${ }^{19}$ Women are traditionally responsible for collecting forest products for subsistence use in the study area, and the low level of PES does not decrease harvest in this relevant group.

The lack of crowding-out effect by the trivially low pecuniary incentive and the crowding-in effects among certain sub-groups opposes the hypothesis of a crowding-out effect of small payments in this context. That the crowding-in effects are not strong enough to have an impact on the aggregate level still support the argument "pay enough or don't pay at all". The reason is not necessarily crowding-out; it is simply - from a conservation viewpoint - a waste of money.

\subsubsection{Increasing PES - how much is enough?}

Under 60\% PES, the observed harvest rate is also significantly below the predictions, but under $100 \%$, the picture is reversed: the observed mean harvest rate is significantly bigher than the predicted harvest rate. Overall, the observed mean harvest rate decreases slower than the predicted harvest rate with higher PES levels. We propose two possible explanations for the diminishing difference between (and eventual reversal of) the observed and individually optimal harvest rate: (i) a reduction in other motivations for forest conservation as the PES level increases, i.e., a crowding-out effect, and (ii) an increase in the relative importance of other

\footnotetext{
18 This finding contradicts the tendency that women respond stronger to experiment treatments (Croson and Gneezy 2009).

${ }^{19}$ In the related experimental study of Handberg and Angelsen (2015), women generally harvest more and are more sensitive to treatments. Still, that women are more true to the prediction than men is consistent with the study.
} 
motivations for forest use, mitigating the price effect of PES on forest use. ${ }^{20}$ We discuss them in turn.

Part of the discrepancy between predicted and observed harvests under $0 \%, 20 \%$, and $60 \%$ PES is due to other motivations for forest conservation, which is an often-encountered interpretation of similar experiment results (Frey 1994, Frey and Oberholzer-Gee 1997, Midler et al. 2015). The discrepancy under 60\% PES is likely lower than under $0 \%$ and $20 \%$ PES, and under $100 \%$ PES, the discrepancy is reversed. This could be driven by the pecuniary incentives for forest conservation crowding-out the other motivations; the stronger the incentives, the stronger the crowding-out effect. Thus, it is observed at high level and not at the low level of PES.

Other motivations for forest conservation at 100\% PES is, by design, not observable; the harvest rate cannot be negative. Notably, all counterfactuals affecting the rate (e.g., participants making uninformed decisions or scrutiny affecting their behaviour) will bias the harvest rate upwards. This design feature thus drives at least part of the significantly positive mean harvest rate.

Other motivations for forest use provides an alternative explanation. Rural Tanzanian households rely on firewood and other products from the forest. The framing of the experiment primes the participants to bring this reliance into the experiment, which is indeed an aim of FFEs and helps ensure external validity. Under 100\% PES, $1 / 3$ of the decisions harvest some trees without making any profit on the harvesting. This is also often heard in discussions on forest conservation and REDD+ with rural villagers: "even if you pay us to conserve the forest, we still need firewood". Cash is not perceived as a perfect substitute for firewood.

Correlations between stated absolute and relative forest uses and individual mean harvest rates in the experiment seem to be strongest under 100\% PES (Table 2). This indicates that other motivations for forest use is stronger in this treatment group than under $20 \%$ or $60 \%$ PES and supports the explanation. There is no correlation between commercial forest use and the harvest rate under 100\% PES, which could be due to commercial forest users not having stronger other motivations than non-commercial forest users. After all, their use of forest products is (partly) pecuniary incentivised.

The suggestion that the potential crowding-out effect is stronger at higher payment levels than at lower contradicts relevant literature on the topic (Gneezy and Rustichini 2000, Heyman and Ariely 2004, Bowles and Hwang 2008, Bowles and Polanía-Reyes 2012, Kerr et al. 2012, Rode et al. 2014). If anything, the literature suggests that there is, in sum, crowding-out effects in small payments; for higher payments, the pecuniary incentives dominate.

The harvesting under 100\% PES can be interpreted as a minimum use of forest products needed, irrespective of cash payments. ${ }^{21}$ This implies that further reductions in harvest is difficult. Together with the correlation between stated forest use and harvest decisions in the

\footnotetext{
${ }^{20}$ Other motivations for forest use which reduce the predicted effect of forest conservation interventions is not equivalent to crowding-out of other motivations for reduced forest use. The latter necessities a reduction in other motivations for forest conservation.

${ }^{21}$ By taking this understanding of the results, the harvest rate under 100\% PES (0.14) is the set minimum level of harvest rate. Subtracting this number from the other harvest levels would then reveal forest use above the subsistence requirement.
} 
experiment, the potential framing effects indicate the benefits of a clear framing of the experiment when relating it to the design of real policy interventions. It also emphasises that findings will be context-specific.

Related to needs is the perceived necessity of forest products. Applying mental accounting (Thaler 1985) to forest use predicts that forest users allocate a set amount of forest products for a given time. Our mental accounting budgets output and input in categories. Changing these allocations is challenging, even if the benefits of outputs decrease or the costs of inputs increase. Although the participants under 100\% PES are fully compensated for conserving the forest, they could still decide to harvest trees, as they need to fill their mental account of forest products.

\subsection{External validity}

We find support for the behavioural validity of the experiment in the positive correlation between stated real-life forest use and harvest in the experiment, i.e., participants tend to bring relevant real life situations into the experiment setting. The behavioural validity is further supported by observations from the experiment sessions. Participants tended to harvest trees selectively, as if practicing thinning; i.e., picking trees from different areas of the paper tree forest, instead of the ones closest to the participant. Also, after receiving the instructions, questions asked by some participants indicated the ability to relate the session to real life situations. Questions asked include: "So if I want to grow maize I should just cut many trees to clear the land?" "What about people coming from Mwanza [a nearby city] to cut our trees, how are they included?" "How is other services from the forest included? Like beekeeping?" "If I die, is the PES transferred to my family?" This underscores our claim that FFEs yields results that are relevant for real-life policy making.

Treatment validity refers to the extent treatments relate to their real life counterparts. The stronger the validity, the truer the treatment effects are in predicting real-life impacts of policy interventions. In this experiment, the treatments replicate an individual PES scheme to reduce forest use. One important caveat is that the design tests possible crowding-in or crowding-out effects of pecuniary incentives in a pecuniary incentive framework. Like most economic experiments, the participants were rewarded in cash based on their decisions during the experiment sessions, also in the 0\% PES case. Real life subsistence use of forest products in contrast is by definition cash-free. Thus a possible crowding-out effect is not observed at $20 \%$ PES because other motivations are also crowded out in the comparison group ( $0 \% \mathrm{PES})$. The relatively low mean harvest rate, however, indicates that other motivations are important in making harvest decisions also under $0 \%$ PES. $^{22}$

Finally, the amount of noise is more of an issue in the field than in the lab. We experienced mangoes falling down on a tin roof and scaring participants, village leaders interrupting sessions to ask questions or to make requests, a village leader physically punishing a child just outside the experiment area, and one participant - an elderly woman - screaming and wanting to kill the enumerator! These disturbances are likely to increase the variance, but might also bias the data. For instance, the disturbances could make participants less sure about anonymity and thus

\footnotetext{
22 The paper focuses on individual decisions in a social setting, thus ignoring collective decisions.
} 
increase pro-social behaviour. On balance, such noise is a price worth paying to pay to get data from the noisy field, rather than the sterile university lab.

\section{Conclusions}

Our experiment and analysis yield several findings that are relevant for REDD+, PES schemes and forest conservation more generally in developing countries. First, other motivations for forest conservation likely decrease forest use to below that of a selfish material-maximizing forest user. Second, these other motivations are, nevertheless, often not sufficient to sustain forest stocks. External interventions, such as PES, can thus be justified as a means to ensure a good group outcome and to provide offsite services in the form of carbon sequestration and storage.

Third, other motivations for forest use could maintain forest use even without material payoff motivations. Reaching zero forest use is therefore either costly or infeasible (ignoring the ethical aspect). This is not necessarily limited to PES schemes; research on forest use and protected areas tend to find that exclusion of forest users is challenging (e.g., Laurance et al. 2012).

Fourth, trivially low individual PES decreases forest use among certain sub-groups (relatively rich and men), but not in aggregate and not in sub-groups traditionally more reliant on collecting forest products (poor and women). The lack of any clear support for the crowding-out hypothesis could indicate that the hypothesis underestimates forest users' ability to distinguish between external and other motivations. This supports the notion that possible crowding-out effects are context and domain specific, and should be investigated accordingly.

Fifth, substantial PES levels reduce forest use, but less than the price effect suggests. Higher PES levels gives more forest conservation, but other motivations for forest use and/or lower other motivations for forest conservation diminish the effect. The intuitive, but nonetheless important finding is that different levels of PES impact forest use differently. The level of payment needs to match the level of ambition and conservation target.

Further investigations in natural resource uses should clearly separate between other motivations for conservation and for use. The latter has received less attention than the former in the literature. Framed field experiments (FFEs) could be an important tool in such investigations.

In sum, sufficiently strong incentives serves its purpose in reducing forest use in Tanzania, but the effect is decreasing with increasing PES; the forest users are less sensitive than the price effect suggests. In our context, the hypothesised "pay enough or don't pay at all" should be replaced by "pay little, get little; pay more, get a little more".

\section{Acknowledgment}

We appreciate financial support from the Center for International Forestry Research (CIFOR) and from the Climate Change Impacts, Adaptation and Mitigation (CCIAM) programme, both funded by the Norwegian Agency for Development Cooperation (Norad). We are grateful for comments by Renaud Lapeyre, Driss Ezzine de Blas, Stein Holden and Eirik Romstad. 


\section{References}

Abdi, H. H. (2007). The Bonferonni and Sidák Corrections for Multiple Comparisons. Encyclopedia of Measurement and Statistics. N. Salkind. Thousand Oaks, SAGE Publications: 103-107.

Alix-Garcia, J., A. De Janvry and E. Sadoulet (2008). The role of deforestation risk and calibrated compensation in designing payments for environmental services. Environment and Development Economics, 13(03): 375-394. http://dx.doi.org/10.1017/S1355770X08004336.

Andreoni, J. (1990). Impure Altruism and Donations to Public Goods: A Theory of Warm-Glow Giving. The Economic Journal, 100(401): 464-464. http://dx.doi.org/10.2307/2234133.

Angelsen, A., P. Jagger, R. Babigumira, B. Belcher, N. J. Hogarth, S. Bauch, .. . S. Wunder (2014). Environmental Income and Rural Livelihoods: A Global-Comparative Analysis. World Development, 64: S12-S28. http://dx.doi.org/10.1016/j.worlddev.2014.03.006.

Angelsen, A. and T. K. Rudel (2013). Designing and Implementing Effective REDD + Policies: A Forest Transition Approach. Review of Environmental Economics and Policy, 7(1): 91-113. http://dx.doi.org/10.1093/reep/res022.

Ariely, D., A. Bracha and S. Meier (2009). Doing Good or Doing Well? Image Motivation and Monetary Incentives in Behaving Prosocially. American Economic Review, 99(1): 544-555. http://dx.doi.org/10.1257/aer.99.1.544.

Bénabou, R. and J. Tirole (2003). Intrinsic and Extrinsic Motivation. Review of Economic Studies, 70(3): 489-520. http://dx.doi.org/10.1111/1467-937X.00253.

Bénabou, R. and J. Tirole (2006). Incentives and Prosocial Behavior. American Economic Review, 96(5): 1652-1678. http://dx.doi.org/10.1257/aer.96.5.1652.

Benz, M. and S. Meier (2008). Do people behave in experiments as in the field?-evidence from donations. Experimental Economics, 11(3): 268-281.

Blomley, T. and S. Iddi (2009). Participatory Forest Management in Tanzania: 1993-2009. Dar es Salaam, Ministry of Natural Resources and Tourism, Forestry and Beekeeping Division.

Bolton, G. E. and A. Ockenfels (2000). ERC: A Theory of Equity, Reciprocity, and Competition. American Economic Review, 90(1): 166-193. http://dx.doi.org/10.1257/aer.90.1.166.

Bowles, S. and S.-H. Hwang (2008). Social preferences and public economics: Mechanism design when social preferences depend on incentives. Journal of Public Economics, 92(8-9): 18111820. http://dx.doi.org/10.1016/j.jpubeco.2008.03.006.

Bowles, S. and S. Polanía-Reyes (2012). Economic Incentives and Social Preferences: Substitutes or Complements? Journal of Economic Literature, 50(2): 368-425. http://dx.doi.org/10.1257/jel.50.2.368.

Cardenas, J.-C. (2000). How do groups solve local commons dilemmas? Lessons from experimental economics in the field. Environment, Development and Sustainability, 2(3-4): 305-322. http://dx.doi.org/10.1023/A:1011422313042.

Cardenas, J.-C. (2004). Norms from outside and from inside: an experimental analysis on the governance of local ecosystems. Forest Policy and Economics, 6(3-4): 229-241. http://dx.doi.org/10.1016/i.forpol.2004.03.006.

Cardenas, J.-C., J. Stranlund and C. Willis (2000). Local Environmental Control and Institutional Crowding-Out. World Development, 28(10): 1719-1733. http://dx.doi.org/10.1016/S0305750X(00)00055-3.

Cardenas, J. C., A. Dreber, E. von Essen and E. Ranehill (2014). Gender and cooperation in children: experiments in Colombia and Sweden. PLoS One, 9(3): e90923. http://dx.doi.org/10.1371/journal.pone.0090923.

Croson, R. and U. Gneezy (2009). Gender Differences in Preferences. Journal of Economic Literature, 47(2): 448-474. http://dx.doi.org/10.1257/jel.47.2.448. 
Deci, E. L., R. Koestner and R. M. Ryan (1999). A meta-analytic review of experiments examining the effects of extrinsic rewards on intrinsic motivation. Psychological Bulletin, 125(6): 627-668; discussion 692-700.

Ekström, M. (2012). Do watching eyes affect charitable giving? Evidence from a field experiment. Experimental Economics, 15(3): 530-546. http://dx.doi.org/10.1007/s10683011-9312-6.

Ezzine-de-blas, D., E. Corbera and R. Lapeyre (this issue). Crowding-in or crowding-out? A conceptual framework to understand motivations in payments for ecosystem services. TBD.

FAO (2001). Global Forest Resources Assessment 2000: Main Report. Rome, The Food and Agriculture Organization (FAO).

FAO (2011). State of the world's forests. Rome, The Food and Agriculture Organization (FAO).

FAO (2012). State of the world's forests. Rome, The Food and Agriculture Organization (FAO).

Fehr, E. and A. Falk (2002). Psychological foundations of incentives. European Economic Review, 46(4-5): 687-724. http://dx.doi.org/10.1016/S0014-2921(01)00208-2.

Fehr, E. and S. Gächter (2000). Fairness and retaliation: The economics of reciprocity. Journal of Economic Perspectives, 14(3): 159-182. http://dx.doi.org/10.1257/jep.14.3.159.

Frey, B. S. (1994). How Intrinsic Motivation is Crowded out and in. Rationality and Society, 6(3): 334-352. http://dx.doi.org/10.1177/1043463194006003004.

Frey, B. S. and R. Jegen (2001). Motivation Crowding Theory. Journal of Economic Surveys, 15(5): 589-611. http://dx.doi.org/10.1111/1467-6419.00150.

Frey, B. S. and F. Oberholzer-Gee (1997). The cost of price incentives: An empirical analysis of motivation crowding-out. American Economic Review, 87(4): 746-755.

Gneezy, U. and A. Rustichini (2000). Pay enough or don't pay at all. Quarterly Journal of Economics, 115(3): 791-810. http://dx.doi.org/10.1162/003355300554917.

Handberg, Ø. N. and A. Angelsen (2015). Experimental tests of tropical forest conservation measures. Journal of Economic Behavior \& Organization, 118. http://dx.doi.org/10.1016/i.jebo.2015.03.007.

Harrison, G. W. and J. A. List (2004). Field experiments. Journal of Economic Literature, 42(4): 1009-1055. http://dx.doi.org/10.1257/0022051043004577.

Henrich, J., S. J. Heine and A. Norenzayan (2010). The weirdest people in the world? The Behavioral and brain sciences, 33(2-3): 61-83; discussion 83-135. http://dx.doi.org/10.1017/S0140525X0999152X.

Heyman, J. and D. Ariely (2004). Effort for payment. A tale of two markets. Psychological science, 15(11): 787-793. http://dx.doi.org/10.1111/j.0956-7976.2004.00757.x.

Johnsen, F. H. (1999). Burning with enthusiasm: Fuelwood scarcity in Tanzania. Forum for Development Studies, 26(1): 107-131. http://dx.doi.org/10.1080/08039410.1999.9666097.

Kerr, J., M. Vardhan and R. Jindal (2012). Prosocial behavior and incentives: Evidence from field experiments in rural Mexico and Tanzania. Ecological Economics, 73: 220-227. http://dx.doi.org/10.1016/i.ecolecon.2011.10.031.

Laurance, W. F., D. Carolina Useche, J. Rendeiro, M. Kalka, C. J. A. Bradshaw, S. P. Sloan, ... F. Zamzani (2012). Averting biodiversity collapse in tropical forest protected areas. Nature, 489(7415): 290-294. http://dx.doi.org/10.1038/nature11318.

Le Grand, J. (2006). Motivation, agency, and public policy: of knights and knaves, pawns and queens. Oxford, Oxford University Press.

Lepper, M. R. and D. Greene (1978). The hidden costs of reward: New perspectives on the psychology of buman motivation. Hillsdale, Lawrence Erlbaum Associates.

Levitt, S. D. and J. A. List (2007). What do laboratory experiments measuring social preferences reveal about the real world? Journal of Economic Perspectives, 21(2): 153-174.

http://dx.doi.org/10.1257/jep.21.2.153. 
Lund, J. F. and T. Treue (2008). Are We Getting There? Evidence of Decentralized Forest Management from the Tanzanian Miombo Woodlands. World Development, 36(12): 27802800. http://dx.doi.org/10.1016/j.worlddev.2008.01.014.

Lusk, J. L., J. R. Pruitt and B. Norwood (2006). External validity of a framed field experiment. Economics Letters, 93(2): 285-290. http://dx.doi.org/10.1016/j.econlet.2006.05.016.

Martin, R. and J. Randal (2011). How Social Norms, Price, and Scrutiny Influence Donation Behavior: Evidence from Four Natural Field Experiments. The science of giving: Experimental approaches to the study of charity D. M. Oppenheimer and C. Y. Olivola. New York, Psychology Press: 81-113.

Midler, E., U. Pascual, A. G. Drucker, U. Narloch and J. L. Soto (2015). Unraveling the effects of payments for ecosystem services on motivations for collective action. Ecological Economics. http://dx.doi.org/10.1016/j.ecolecon.2015.04.006.

Muradian, R., M. Arsel, L. Pellegrini, F. Adaman, B. Aguilar, B. Agarwal, . . K. Urama (2013). Payments for ecosystem services and the fatal attraction of win-win solutions. Conservation Letters, 6(4): 274-279. http://dx.doi.org/10.1111/j.1755-263X.2012.00309.x.

Narloch, U., U. Pascual and A. G. Drucker (2012). Collective Action Dynamics under External Rewards: Experimental Insights from Andean Farming Communities. World Development, 40(10): 2096-2107. http://dx.doi.org/10.1016/j.worlddev.2012.03.014.

Ostrom, E., R. Gardner and J. M. Walker (1994). Rules, games, and common-pool resources. Ann Arbor, University of Michigan Press.

Pattanayak, S. K., S. Wunder and P. J. Ferraro (2010). Show Me the Money: Do Payments Supply Environmental Services in Developing Countries? Review of Environmental Economics and Policy, 4(2): 254-274. http://dx.doi.org/10.1093/reep/req006.

Rode, J., E. Gómez-Baggethun and T. Krause (2014). Motivation crowding by economic incentives in conservation policy: A review of the empirical evidence. Ecological Economics, 109. http://dx.doi.org/10.1016/i.ecolecon.2014.11.019.

Rodriguez-Sickert, C., R. A. Guzmán and J.-C. Cardenas (2008). Institutions influence preferences: Evidence from a common pool resource experiment. Journal of Economic Behavior \& Organization, 67(1): 215-227. http://dx.doi.org/10.1016/i.jebo.2007.06.004.

Ryan, R. M. and E. L. Deci (2000a). Intrinsic and Extrinsic Motivations: Classic Definitions and New Directions. Contemporary educational psychology, 25(1): 54-67. http://dx.doi.org/10.1006/ceps.1999.1020.

Ryan, R. M. and E. L. Deci (2000b). Self-determination theory and the facilitation of intrinsic motivation, social development, and well-being. The American Psychologist, 55(1): 68-78. http://dx.doi.org/10.1037/0003-066X.55.1.68.

Simonson, I. (1989). Choice Based on Reasons: The Case of Attraction and Compromise Effects. Journal of Consumer Research, 16(2): 158-174. http://dx.doi.org/10.1086/209205.

Stern, N. (2006). Stern Review: The economics of climate change. Cambridge, Cambridge University Press.

Sunderland, T., R. Achdiawan, A. Angelsen, R. Babigumira, A. Ickowitz, F. Paumgarten, ... G. Shively (2014). Challenging Perceptions about Men, Women, and Forest Product Use: A Global Comparative Study. World Development, 64: S56-S66. http://dx.doi.org/10.1016/i.worlddev.2014.03.003.

Thaler, R. (1985). Mental Accounting and Consumer Choice. Marketing Science, 4(3): 199-214.

Titmuss, R. M. (1970). The Gift Relationship: From Human Blood to Social Policy. London, Allen and Unwin.

TNRF (2009). Using the nation's resources to reduce poverty? Arusha, Tanzania Natural Resource Forum (TNRF).

Treue, T., Y. M. Ngaga, H. Meilby, J. F. Lund, G. Kajembe, S. Iddi, . . N. D. Burgess (2014). Does participatory forest management promote sustainable forest utilisation in Tanzania? 
International Forestry Review, 16(1): 23-38.

http://dx.doi.org/10.1505/146554814811031279.

URT (2012). National strategy for reduced emissions from deforestation and forest degradation (REDD+).

Dar es Salaam, Vice president's office, United Republic of Tanzania (URT).

Vollan, B. (2008). Socio-ecological explanations for crowding-out effects from economic field experiments in southern Africa. Ecological Economics, 67(4): 560-573.

http://dx.doi.org/10.1016/j.ecolecon.2008.01.015.

World Bank (2008). Putting Tanzania's bidden economy to work: Reform, management, and protection of its natural resource sector. Washington D.C., World Bank.

World Bank (2010). Enabling Reforms: A Stakeholder-Based Analysis of the Political Economy of Tanzania's Charcoal Sector and the Poverty and Social Impacts of Proposed Reforms. Washington D.C., World Bank.

Wunder, S. (2013). When payments for environmental services will work for conservation. Conservation Letters, 6(4): 230-237. http://dx.doi.org/10.1111/conl.12034.

Wunder, S. (2015). Revisiting the concept of payments for environmental services. Ecological Economics, 117: 234-243. http://dx.doi.org/10.1016/i.ecolecon.2014.08.016.

Zahabu, E., T. Eid, G. Kajembe, L. Mbwambo, C. Mongo, A. Sangeda, . . E. Luoga (2009). Forestland tenure systems in Tanzania: an overview of policy changes in relation to forest management. IN A fagrapport, No.14.

\section{Appendix I: Theoretical predictions}

The following tables reports the material outcomes for a given participants after the nine rounds of a session, given specific strategies of the participant and the other participants in the same session. The numbers are the TZS participant $i$ earns in the session given her/his strategy and the mean strategy of the others, $x_{j}$.

The outcomes are derived by simulating six different strategies by the participant in question (columns) and the same six strategies as the mean strategy employed by the other seven participants (rows). The strategies are presented as fractions of the maximum harvest. If $\max \left(x_{i}\right)=5$ through the rounds, $\frac{\max \left(x_{i}\right)}{1.5}=3 \frac{1}{3}$. In any strategy, $\max \left(x_{i}\right)=\max \left(x_{j}\right)$.

For instance, the outcome in the top left corner is derived by simulating a maximum harvest strategy (harvesting at the upper limit) by participant $i$ and as the mean of remaining seven participants in the session, $j$. In the first round, 40 trees are harvested, leaving 40 trees. Two trees for every ten tree is added, increasing the forest stock to 48 trees before round two. In this round, 40 trees are again harvested, leaving eight trees. There is no forest growth as the stock is below 10 trees. In the third round, the participants can maximum take one tree each. This depletes the forest stock and ends the experiment. Participant $i$ earned 5*100 TZS in each of rounds one and two, and 100 TZS in round three, making the total outcome 1100 TZS.

The red squares indicate the highest payoff and thus the optimal strategy given the strategies of others. Table 10 reports the potential outcomes under no PES, Table 11 for 20\% PES, Table 12 for 60\% PES and Table 13 for 100\% PES.

An alternative approach takes the starting point of participants facing the harvesting choice in round one. Here the participants have no prior information indicating the average choices of 
others. Thus, the beliefs will centre around the mean $\left(\frac{\operatorname{Max}(x i)}{2}\right)$. Finding the optimal strategies in this column of the above tables reveals the same outcomes as indicated above. Under $0 \%$ and $20 \%$ PES the optimal strategy is to maximize harvest, under 60\% PES the optimal strategy is to reciprocate and also harvest half of the limit, and under 100\% PES the optimal strategy is to not harvest any trees.

Table 10: Optimal harvesting strategies $\mathrm{x}$ for individual $\boldsymbol{i}$ under no PES given the strategies of others $\mathrm{x}_{j}$

\begin{tabular}{l|llllll}
\hline \multicolumn{1}{c}{$x_{i}$} & $\operatorname{Max}\left(x_{i}\right)$ & $\operatorname{Max}\left(x_{i}\right) / 1.5$ & $\operatorname{Max}\left(x_{i}\right) / 2$ & $\operatorname{Max}\left(x_{i}\right) / 2.5$ & $\operatorname{Max}\left(x_{i}\right) / 3$ & $\operatorname{Min}\left(x_{i}\right)$ \\
\hline $\operatorname{Max}\left(x_{j}\right)$ & 1100 & 733 & 550 & 480 & 400 & 0 \\
$\operatorname{Max}\left(x_{j}\right) / 1.5$ & 1600 & 1133 & 900 & 760 & 667 & 0 \\
$\operatorname{Max}\left(x_{j}\right) / 2$ & 2300 & 1667 & 1500 & 1200 & 1033 & 0 \\
$\operatorname{Max}\left(x_{j}\right) / 2.5$ & 3100 & 2400 & 1900 & 1640 & 1367 & 0 \\
$\operatorname{Max}\left(x_{j}\right) / 3$ & 3800 & 2867 & 2250 & 1800 & 1500 & 0 \\
$\operatorname{Min}\left(x_{j}\right)$ & 4500 & 3000 & 2250 & 1800 & 1500 & 0 \\
\hline
\end{tabular}

Table 11: Optimal harvesting strategies $\mathrm{x}$ for individual $\boldsymbol{i}$ under low payment (20\%) given the strategies of others $\mathrm{x}_{j}$

\begin{tabular}{lllllll}
\hline \multicolumn{1}{c}{$x_{i}$} & \multicolumn{1}{c}{$\operatorname{Max}\left(x_{i}\right)$} & $\operatorname{Max}\left(x_{i}\right) / 1.5$ & $\operatorname{Max}\left(x_{i}\right) / 2$ & $\operatorname{Max}\left(x_{i}\right) / 2.5$ & $\operatorname{Max}\left(x_{i}\right) / 3$ & $\operatorname{Min}\left(x_{i}\right)$ \\
\hline $\operatorname{Max}\left(x_{j}\right)$ & 1100 & 807 & 660 & 624 & 560 & 240 \\
$\operatorname{Max}\left(x_{j}\right) / 1.5$ & 1600 & 1247 & 1080 & 988 & 933 & 440 \\
$\operatorname{Max}\left(x_{j}\right) / 2$ & 2300 & 1833 & 1800 & 1560 & 1447 & 700 \\
$\operatorname{Max}\left(x_{j}\right) / 2.5$ & 3100 & 2640 & 2280 & 2132 & 1913 & 900 \\
$\operatorname{Max}\left(x_{j}\right) / 3$ & 3800 & 3153 & 2700 & 2340 & 2100 & 900 \\
$\operatorname{Min}\left(x_{j}\right)$ & 4500 & 3300 & 2700 & 2340 & 2100 & 900 \\
\hline
\end{tabular}

Table 12: Optimal harvesting strategies $\mathrm{x}$ for individual $i$ under $m$ payment (60\%) given the strategies of others $\mathrm{x}_{j}$

\begin{tabular}{l|lllllll}
\hline \multicolumn{1}{c}{$x_{i}$} & $\operatorname{Max}\left(x_{i}\right)$ & $\operatorname{Max}\left(x_{i}\right) / 1.5$ & $\operatorname{Max}\left(x_{i}\right) / 2$ & $\operatorname{Max}\left(x_{i}\right) / 2.5$ & $\operatorname{Max}\left(x_{i}\right) / 3$ & $\operatorname{Min}\left(x_{i}\right)$ \\
\hline $\operatorname{Max}\left(x_{j}\right)$ & 1100 & 953 & 880 & 912 & 880 & 720 \\
$\operatorname{Max}\left(x_{j}\right) / 1.5$ & 1600 & 1473 & 1440 & 1444 & 1467 & 1320 \\
$\operatorname{Max}\left(x_{j}\right) / 2$ & 2300 & 2167 & 2400 & 2280 & 2273 & 2100 \\
$\operatorname{Max}\left(x_{j}\right) / 2.5$ & 3100 & 3120 & 3040 & 3116 & 3007 & 2700 \\
$\operatorname{Max}\left(x_{j}\right) / 3$ & 3800 & 3727 & 3600 & 3420 & 3300 & 2700 \\
$\operatorname{Min}\left(x_{j}\right)$ & 4500 & 3900 & 3600 & 3420 & 3300 & 2700 \\
\hline
\end{tabular}

Table 13: Optimal harvesting strategies $\mathrm{x}$ for individual $\boldsymbol{i}$ under full payment (100\%) given the strategies of others $\mathrm{x}_{j}$

\begin{tabular}{|c|c|c|c|c|c|c|}
\hline$\overbrace{x_{i}}^{x_{i}}$ & $\operatorname{Max}\left(x_{i}\right)$ & $\operatorname{Max}\left(x_{i}\right) / 1.5$ & $\operatorname{Max}\left(x_{i}\right) / 2$ & $\operatorname{Max}\left(x_{i}\right) / 2.5$ & $\operatorname{Max}\left(x_{i}\right) / 3$ & $\operatorname{Min}\left(x_{i}\right)$ \\
\hline $\operatorname{Max}\left(x_{j}\right)$ & 1100 & 1100 & 1100 & 1200 & 1200 & 1200 \\
\hline $\operatorname{Max}\left(x_{j}\right) / 1.5$ & 1600 & 1700 & 1800 & 1900 & 2000 & 2200 \\
\hline $\operatorname{Max}\left(x_{j}\right) / 2$ & 2300 & 2500 & 3000 & 3000 & 3100 & 3500 \\
\hline $\operatorname{Max}\left(x_{j}\right) / 2.5$ & 3100 & 3600 & 3800 & 4100 & 4100 & 4500 \\
\hline $\operatorname{Max}\left(x_{j}\right) / 3$ & 3800 & 4300 & 4500 & 4500 & 4500 & 4500 \\
\hline $\operatorname{Min}\left(x_{j}\right)$ & 4500 & 4500 & 4500 & 4500 & 4500 & 4500 \\
\hline
\end{tabular}




\section{Appendix II: Village attributes and treatment distribution}

\begin{tabular}{|c|c|c|c|c|c|c|c|c|c|}
\hline 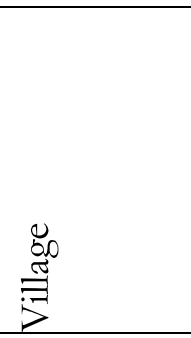 & 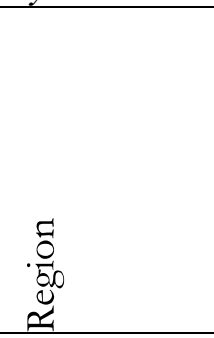 & 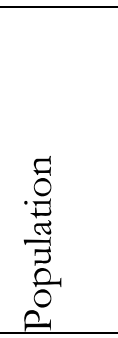 & 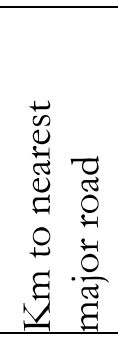 & 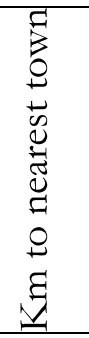 & 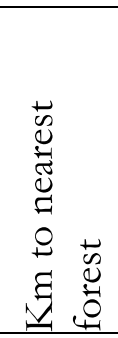 & 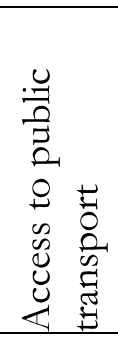 & 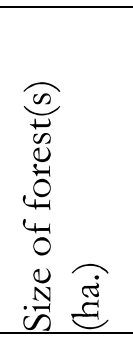 & 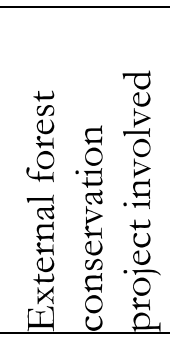 & 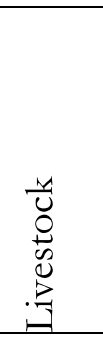 \\
\hline Bugulula & Geita & 8012 & 2 & 10 & 1.5 & Yes & 15737 & No & 7022 \\
\hline Chibingo & Geita & 6016 & 0 & 8 & 1.5 & Yes & $\mathrm{N} / \mathrm{A}$ & No & 1280 \\
\hline Msasa & Geita & 6587 & 8 & 12 & 4 & No & 47800 & No & 2856 \\
\hline Saragulwa & Geita & 12047 & 12 & 36 & 0.5 & Yes & 47700 & Yes & 2725 \\
\hline Bugege & Geita & 1899 & 2.5 & 2.5 & 1 & No & 400000 & No & 508 \\
\hline Kokirie & Kilimanjaro & 3490 & 2 & 30 & 2 & Yes & 107828 & Yes & $\mathrm{N} / \mathrm{A}$ \\
\hline Miwaleni & Kilimanjaro & 1002 & 6.9 & 18 & 0.4 & No & 95 & No & 3037 \\
\hline $\begin{array}{l}\text { Mandaka } \\
\text { Mnono }\end{array}$ & Kilimanjaro & 3600 & 7 & 7 & 4 & No & 2502 & No & 1160 \\
\hline Mtakuja & Kilimanjaro & 5380 & 5 & 12.5 & 12.5 & Yes & 2505 & No & $\mathrm{N} / \mathrm{A}$ \\
\hline Mande & Kilimanjaro & 3100 & 4 & 7 & 1.5 & Yes & 8 & No & 584 \\
\hline Nndawa & Lindi & 973 & 12 & 12 & 2 & No & 969 & Yes & 17 \\
\hline Namupa & Lindi & 1462 & 8 & 8 & 3 & No & 325 & Yes & 3 \\
\hline Ntene A & Lindi & 2299 & 25 & 83 & 2 & Yes & 19834 & Yes & 83 \\
\hline $\begin{array}{l}\text { Rutamba } \\
\text { ya Zamani }\end{array}$ & Lindi & 1925 & 20 & 25 & 1 & Yes & 1326 & No & 337 \\
\hline Simana & Lindi & 3345 & 5 & 8 & 1.5 & No & 320 & No & 80 \\
\hline
\end{tabular}

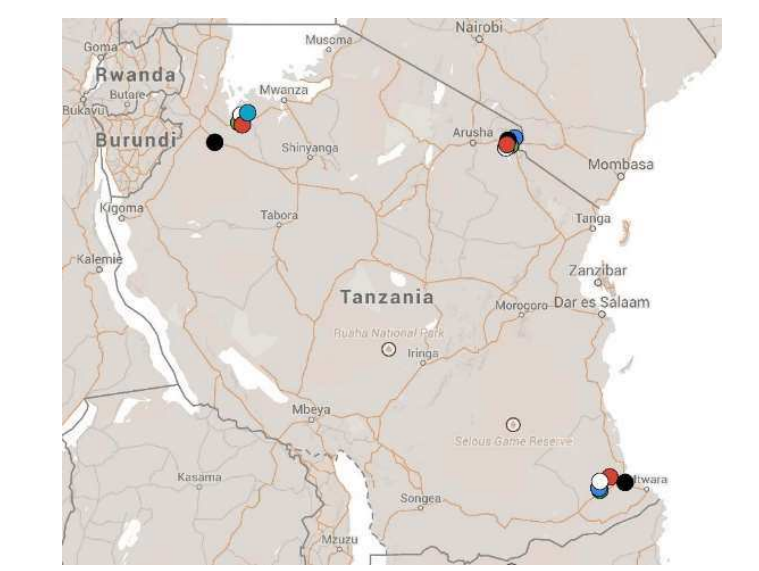

Figure 6: Location of sampled villages (from Google maps)

Table 15: Distribution of treatments by village and sequence in each village

\begin{tabular}{lllll}
\hline Village & First session & Second session & Third session & Fourth session \\
\hline Bugulula & No PES & Full PES & Medium PES & Medium PES \\
Chibingo & Full PES & Low PES & Low PES & No PES \\
Msasa & Low PES & Low PES & Full PES & Medium PES \\
Saragulwa & Medium PES & No PES & Full PES & Full PES \\
Bugege & Low PES & Medium PES & No PES & Medium PES \\
Kokirie & Full PES & Full PES & Medium PES & No PES \\
Miwaleni & No PES & Full PES & Medium PES & Low PES \\
Mandaka Mnono & Medium PES & Medium PES & No PES & Full PES
\end{tabular}




\begin{tabular}{lllll} 
Mtakuja & Low PES & Full PES & No PES & Low PES \\
Mande & Low PES & No PES & Full PES & Low PES \\
Nndawa & Medium PES & No PES & Medium PES & Full PES \\
Namupa & No PES & Low PES & Low PES & Medium PES \\
$\begin{array}{l}\text { Ntene A } \\
\text { Rutamba ya }\end{array}$ & Full PES & Low PES & Low PES & Full PES \\
$\begin{array}{l}\text { Zamani } \\
\text { Simana }\end{array}$ & Full PES & Medium PES & Full PES & Low PES \\
\hline
\end{tabular}

\section{Appendix III: Experiment materials}

Questionnaire

\begin{tabular}{|l}
\hline Basic information \\
\hline Participant no. \\
\hline Age \\
\hline Gender $(1=$ female. $0=$ male $)$ \\
\hline
\end{tabular}

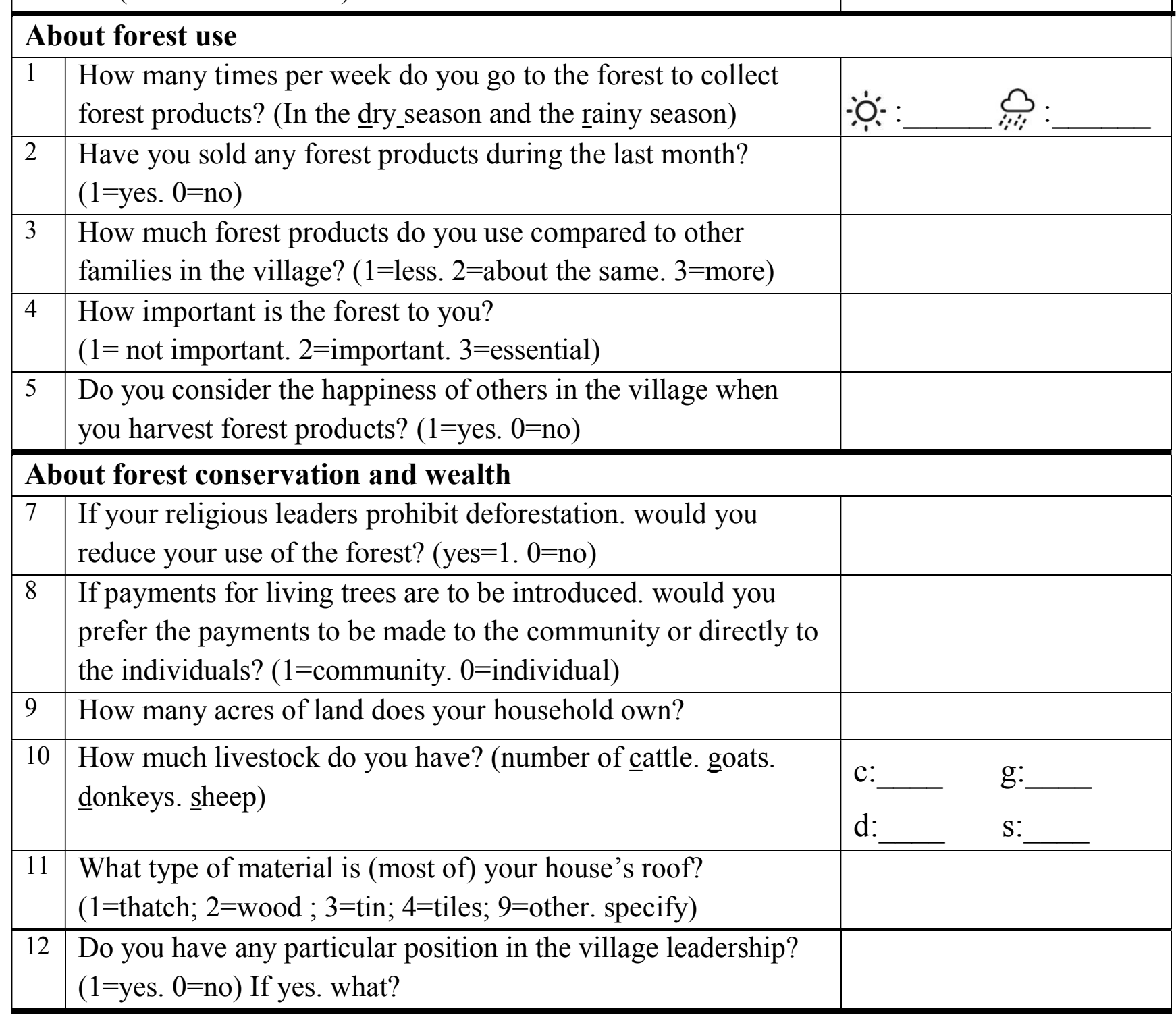




\begin{tabular}{|c|c|c|}
\hline 13 & $\begin{array}{l}\text { Has your household faced any major income shortfalls or } \\
\text { unexpectedly large expenditures during the past } 12 \text { months? } \\
\text { For example: death or serious illness in family. serious crop } \\
\text { failure. lost wage employment. land loss or any other loss? } \\
(0=\text { No. } 1=\text { yes but manageable. } 2=\text { yes severe })\end{array}$ & \\
\hline 14 & $\begin{array}{l}\text { Can you get help from others in the village if you are in need? } \\
\text { For example if you need extra money because someone in your } \\
\text { family is sick? }(0=\text { no. } 1=\text { sometimes. } 2=\text { yes })\end{array}$ & \\
\hline 15 & $\begin{array}{l}\text { Do you in general trust people in the village? }(0=\text { no. } \\
1=\text { sometimes. } 2=\text { yes })\end{array}$ & \\
\hline \multicolumn{2}{|r|}{$\begin{array}{l}\text { I will make some statements. please tell me to what degree } \\
\text { you agree to each claim }\end{array}$} & $\begin{array}{l}5=\text { Strongly agree } / 4=\text { agree/ } \\
3=\text { ambivalent } 2=\text { disagree/ } \\
1=\text { strongly disagree }\end{array}$ \\
\hline 24 & $\begin{array}{l}\text { It is right that those who benefit from the clean air that our } \\
\text { forests produce contribute to conserving the forest. }\end{array}$ & \\
\hline 25 & $\begin{array}{l}\text { It is not proven that paying for living trees decreases } \\
\text { deforestation. }\end{array}$ & \\
\hline 26 & $\begin{array}{l}\text { Paying for living trees make other forest use considerations less } \\
\text { important; like tradition. culture and religion. }\end{array}$ & \\
\hline 27 & $\begin{array}{l}\text { The village council is doing the best possible actions to } \\
\text { improve the lives of its inhabitants. }\end{array}$ & \\
\hline \multicolumn{2}{|c|}{ About the experiment } & \\
\hline 28 & I felt like I owned the forest. & \\
\hline 29 & I felt like I owned the forest conservation project & \\
\hline 30 & $\begin{array}{l}\text { Did you participate together with any close friends or family in } \\
\text { the experiment? }(1=\text { yes. } 0=\text { no) If yes. how many? }\end{array}$ & \\
\hline 31 & $\begin{array}{l}\text { Did you have any particular harvest strategy in the experiment? } \\
\text { Why/why not? }\end{array}$ & \\
\hline 32 & $\begin{array}{l}\text { I am going to say four letters. Please indicate your first. } \\
\text { intuitive reaction to them: rate them by likeability ( } 5=\text { strongly } \\
\text { like. } 4=\text { like. } 3=\text { ambivalent. } 2=\text { dislike. } 1=\text { strongly dislike): }\end{array}$ & $\begin{array}{l}\mathrm{E}: \\
\overline{\left(1^{\text {st }}\right.} \text { letter of } 1^{\text {st }} \\
\text { letter not in names })\end{array}$ \\
\hline 33 & Do you know how to read and write? $(1=$ yes. $0=$ no $)$ & \\
\hline
\end{tabular}


Maximum harvest table

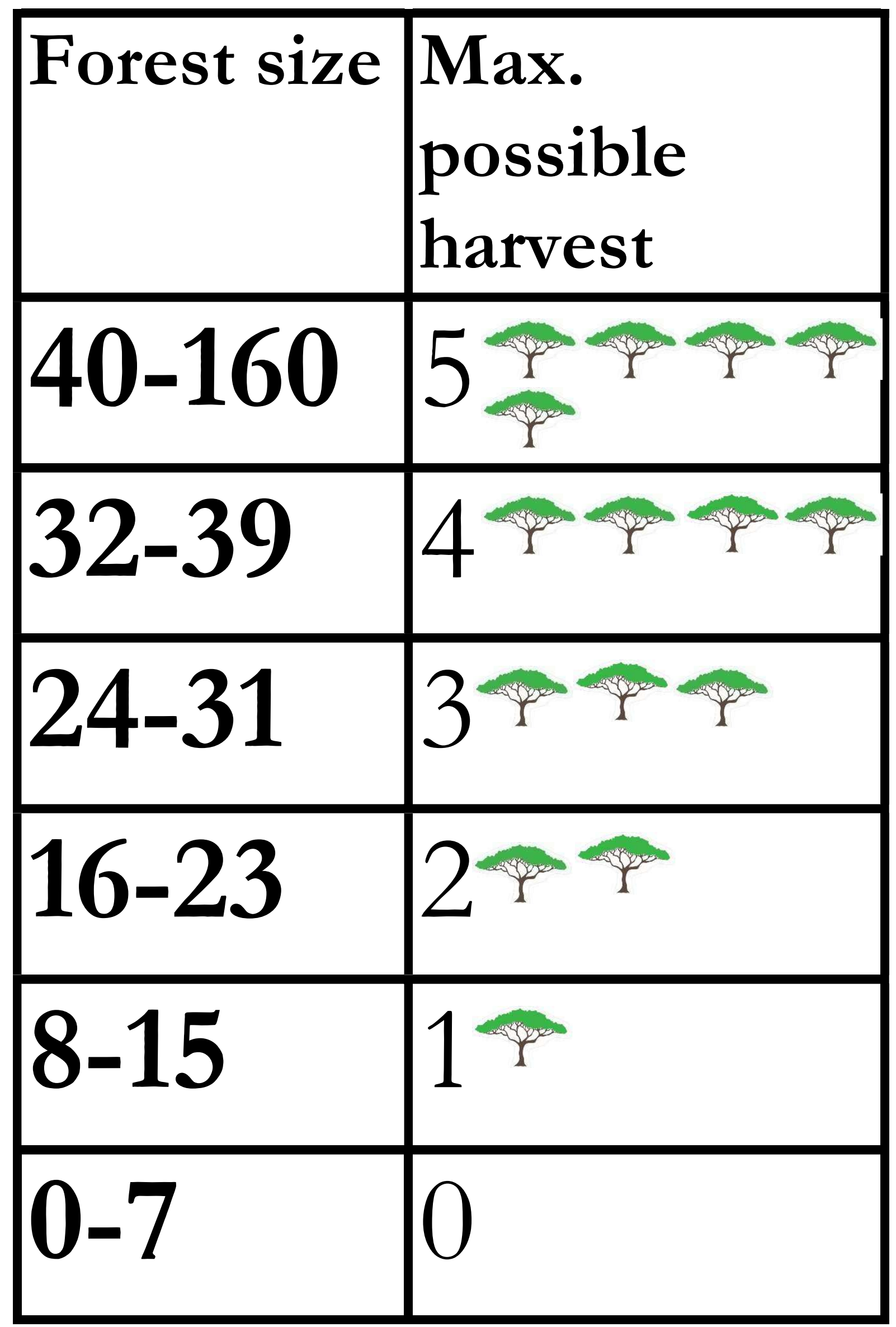




\section{Instructions}

Thank you everyone for accepting this invitation. We will spend almost three hours explaining the activity. playing and conducting a short survey at the end. Let's start!

The following exercise is a different and entertaining way to actively participate in a project about forests. Besides participating in this exercise and earning money. you will answer a few questions afterwards. The funds to cover the expenses have been donated by a scientific body. The reason why we use money and paper trees is to create situations as similar to your real life situations as possible

The situation is one where a group. you. must make decisions about the use of a forest. You have been selected and asked to participate in a random draw from a list of all families in this village. This is done to make sure that all have the same chance of participating.

This exercise is different than exercises in which other persons in this community or others may have played already. Therefore. comments you have heard from other persons do not necessarily apply to this exercise.

Please pay a lot of attention to the instructions. If you understand the instructions. you will be able to make better decisions in the exercise. Please. remain seated and do not speak with other participants. If you have a question. raise your hand and we will answer your question.

So to the experiment. let's pretend this group has a forest of initially these 80 trees [point to the paper trees]. For 9 rounds. equivalent to for example years or wood harvest seasons. each of you will enter the forest and decide how many trees to harvest. You will each earn 100 shillings for each tree you decide to harvest. Think of this as equivalent to firewood. charcoal. timber etc. You can harvest a minimum of 0 trees from the forest and a maximum given by this table [Show the maximum harvest table]. You indicate how many trees you harvest by picking them [Show how trees are harvested]. The trees will be put up temporarily after you have harvested. such that each of you faces the same forest size.

After all of you have privately and anonymously harvested trees in one round. you are all gathered here and the total number of removed trees in that round is announced.

Then the forest grows: for every 10 standing trees. 2 trees are added. [Show how trees are added]

[If in treatment group 1-3:]

You will get an additional payment of your choice. There will be a referendum to ensure that you get the payment you want. You will get 3 minutes to discuss together. Then you will vote in in private on which payment you want.

You can choose between:

- Sell half of your trees. The 40 trees are valued at 2000 shillings. meaning you will be earn 250 shillings before the exercise starts. The forest is then decreased to 40 trees.

OR

- You will be paid for not harvested trees. Since another country also benefits from your forest they would like to contribute to forest conservation. and therefore offer you a forest 
conservation payment. In addition to earning what we have already said. you will get [20/ 60/ 100] shillings for each tree you decide not to harvest. Therefore. if you decide to harvest 2 trees and you could have harvested 5 trees you will earn 200 shillings for the harvested trees. as before. But in addition you will earn [60/ 180/300] shillings for the 3 trees you did not harvest.

[Leave the participants alone for 3 minutes. Then they indicate their choice in private. After the referendum is held:] you have chosen to introduce [chosen payment]. Why did you choose this payment and not the other? [Note reasons]

[If in treatment group 4-6:]

You will get an additional payment. Instead of selling trees you will get paid for not harvested trees. Since other countries also benefit from your forest they would like to contribute to forest conservation. and therefore offer you a forest conservation payment. In addition to earning what we have already said. you will get [20/60/ 100] shillings for each tree you decide not to harvest. Therefore. if you decide to harvest 2 trees and you could have harvested 5 trees you will earn 200 shillings for the harvested trees. as before. In addition you will earn [60/ 180/ 300] shillings for the 3 trees you did not harvest. You now get 3 minutes in private where you can discuss the exercise.

[If in control group (7):]

You now get 3 minutes in private where you can discuss the exercise.

An example [Show as you explain]: Suppose that each of you harvests 3 trees each. When all of you are gathered here we then see that 24 trees are removed. leaving 56 trees. You each earn 300 shillings from the 3 harvested trees.

[If in group 1-3:]

In addition. as you have decided: you will receive [40/120/200] shillings from the forest conservation project.

[If in group 4-6:]

In addition: you will receive [40/ 120/200] shillings from the forest conservation project.

Afterwards. the forest grows by 10 trees to 66. Round 1 of a total of 9 rounds is then completed. Remember that everything you do is anonymous. so nobody can find out how much you harvest. Any questions? [Answer all questions]

Let us try a practice round! This is just for learning so you will not earn anything from this round. [Complete a full round. Answer any further questions]

Ok. now we reset the forest to 80 trees. and start the real exercise. Anything you will earn from now on will be noted and paid to you in real money at the end of the exercise. 